\title{
Sustained Helicobacter pylori infection accelerates gastric dysplasia in a mouse model
}

\author{
Valerie P O'Brien ${ }^{1}$, Amanda L Koehne ${ }^{2,3}$, Julien Dubrulle ${ }^{4}$, Armando E Rodriguez ${ }^{1}$, Christina K Leverich', V Paul Kong ${ }^{3}$, \\ Jean S Campbell ${ }^{5}$, Robert H Pierce ${ }^{5}$, James R Goldenring ${ }^{6,7}$, Eunyoung Choi ${ }^{6}$, Nina R Salama ${ }^{1}$ (1)
}

\begin{abstract}
More than $80 \%$ of gastric cancer is attributable to stomach infection with Helicobacter pylori (Hp). Gastric preneoplastic progression involves sequential tissue changes, including loss of parietal cells, metaplasia and dysplasia. In transgenic mice, active KRAS expression recapitulates these tissue changes in the absence of $\mathrm{HP}$ infection. This model provides an experimental system to investigate additional roles of $H p$ in preneoplastic progression, beyond its known role in initiating inflammation. Tissue histology, gene expression, the immune cell repertoire, and metaplasia and dysplasia marker expression were assessed in KRAS+ mice + / - Hp infection. Hp+/KRAS + mice had severe T-cell infiltration and altered macrophage polarization; a different trajectory of metaplasia; more dysplastic glands; and greater proliferation of metaplastic and dysplastic glands. Eradication of $\mathrm{Hp}$ with antibiotics, even after onset of metaplasia, prevented or reversed these tissue phenotypes. These results suggest that gastric preneoplastic progression differs between $\mathrm{Hp}+$ and $\mathrm{Hp}-$ cases, and that sustained $\mathrm{Hp}$ infection can promote the later stages of gastric preneoplastic progression.
\end{abstract}

DOI 10.26508/Isa.202000967 | Received 19 November 2020 | Revised 23 November 2020 | Accepted 24 November 2020 | Published online 11 December 2020

\section{Introduction}

About $13 \%$ of the global cancer burden in 2018 was attributable to carcinogenic infections (de Martel et al, 2020), and Helicobacter pylori $(\mathrm{Hp})$-associated gastric cancer accounted for the largest proportion of these cancers (Plummer et al, 2015). More than $77 \%$ of new gastric cancer cases, and more than $89 \%$ of new non-cardiac gastric cancer cases, were attributable to infection with $\mathrm{Hp}$ (de Martel et al, 2020), a bacterium that colonizes the stomach of half the world's population (Suerbaum et al, 2002). However, Hp infection confers only a 1-2\% lifetime risk of developing stomach cancer (Kuipers, 1999) and thus a complex interplay between the bacterium and host is presumed to lead to cancer development in only some individuals.

The exact mechanisms through which $\mathrm{Hp}$ infection promotes gastric cancer remain largely elusive. Hp infection typically occurs during childhood and always causes chronic inflammation (gastritis) (Kusters et al, 2006). Hp-dependent chronic inflammation promotes the accumulation of reactive oxygen species and other toxic products that cause mutations in gastric epithelial cells (Chaturvedi et al, 2004, 2011; Allen et al, 2005). Early studies using tissue histology rarely detected $\mathrm{Hp}$ in tumors, leading to a belief that $\mathrm{Hp}$ triggers the initial inflammatory insult in the stomach, but that $\mathrm{Hp}$ is essentially irrelevant by the time gastric cancer is detected; in other words, once chronic gastric inflammation develops and oncogenic pathways are activated, the presence of $\mathrm{Hp}$ is no longer necessary to promote metaplastic changes that lead to cancer. However, more sensitive molecular methods detect $\mathrm{Hp}$ in about half of tumors (Tang et al, 2005; Cristescu et al, 2015; Talarico et al, 2018), and eradication of $\mathrm{Hp}$ combined with tumor resection helps prevent tumor recurrence (Choi et al, 2018), suggesting that Hp may promote the later stages of metaplasia and cancer development in at least some individuals.

Beyond eliciting oncogenic mutations, the mechanism(s) through which chronic gastritis might promote gastric cancer development is not well understood (Salama et al, 2013). Humans generally develop a strong $T_{h} 1$ and $T_{h} 17$ immune response against $\mathrm{Hp}$ that helps control the infection (Akhiani et al, 2002; Sayi et al, 2009; Velin et al, 2009). This T-cell response does not clear the infection and furthermore can drive immunopathology in the gastric mucosa (Stoicov et al, 2009; Shi et al, 2010), and Hp infection can disrupt normal T-cell function through multiple mechanisms (Gebert et al, 2003; Das et al, 2006; Salama et al, 2013). Thus, T cells can play both protective and detrimental roles during $\mathrm{Hp}$ stomach infection. More broadly, anticancer immunity in the context of gastric cancer is not well understood. A better understanding of how active $\mathrm{Hp}$ infection may impact

\footnotetext{
${ }^{1}$ Fred Hutchinson Cancer Research Center, Human Biology Division, Seattle, WA, USA ${ }^{2}$ Fred Hutchinson Cancer Research Center, Comparative Medicine Shared Resource, Seattle, WA, USA ${ }^{3}$ Fred Hutchinson Cancer Research Center, Experimental Histopathology Shared Resource, Seattle, WA, USA ${ }^{4}$ Fred Hutchinson Cancer Research Center, Genomics and Bioinformatics Shared Resource, Seattle, WA, USA ${ }^{5}$ Fred Hutchinson Cancer Research Center, Program in Immunology, Seattle, WA, USA ${ }^{6}$ Department of Surgery, Epithelial Biology Center, Department of Cell and Developmental Biology, Vanderbilt University School of Medicine, Nashville, TN, USA ${ }^{7}$ Nashville Veterans Affairs Medical Center, Nashville, TN, USA
}

Correspondence: nsalama@fredhutch.org 
gastric inflammation in the context of metaplasia and cancer development may lead to the discovery of new drug targets or therapeutic strategies.

The Mist1-Kras mouse is one of the only existing mouse models to recapitulate the progression from healthy gastric epithelium to spasmolytic polypeptide-expressing metaplasia (SPEM), intestinal metaplasia (IM), and dysplasia (Choi et al, 2016). This model uses KRAS, a GTPase signaling protein of the Ras (Rat Sarcoma) family that regulates cell survival, proliferation, and differentiation (Campbell et al, 1998; Jackson et al, 2001). Molecular profiling studies have shown that about $40 \%$ of gastric tumors have signatures of RAS activity (Deng et al, 2012; Cancer Genome Atlas Research Network, 2014). In the mouse model, treatment with tamoxifen (TMX) induces the expression of a constitutively active Kras allele (G12D) in the gastric chief cells. Within 1 mo, SPEM develops in 95\% of corpus glands, and over the next 3 mo progresses to IM (Choi et al, 2016). Thus, active KRAS expression in mice serves as a tool to recapitulate changes that, in humans, are induced by years of inflammation due to $\mathrm{Hp}$ infection. We used Mist1-Kras mice to test our hypothesis that $\mathrm{Hp}$, if present during metaplasia and dysplasia, could impact pathology. We found that, counter to the belief that $\mathrm{Hp}$ is only important for initiating inflammation, sustained $\mathrm{Hp}$ infection coupled with active KRAS expression led to severe inflammation, altered metaplasia marker expression, and increased cell proliferation and dysplasia compared with $\mathrm{Hp}-$ /KRAS+ mice. Thus, the course of gastric neoplastic progression may differ depending on whether $\mathrm{Hp}$ is present during the later stages of disease progression.

\section{Results}

\section{Hp infection worsens gastric immunopathology in mice expressing active KRAS}

To assess whether Hp impacts KRAS-driven metaplasia, we performed concomitant infection/induction experiments in Mist1-Kras mice. First mice were infected with $\mathrm{Hp}$, or mock-infected, and the next day the mice were treated with tamoxifen (TMX) to induce active KRAS expression in stomach chief cells, or sham-induced. After 2, 6, or 12 wk, mice were humanely euthanized and stomachs were aseptically harvested and used for downstream analyses (Fig 1). Formalin-fixed, paraffin-embedded (FFPE) tissue sections were used for histological analysis of the corpus (Fig 2), where active KRAS is expressed in TMX-induced Mist1-Kras mice. Compared with $\mathrm{Hp}$-/KRAS- mice (Fig 2A and B), Hp infection alone caused modest inflammation at 2 wk that increased over time, with loss of parietal cells by 6 wk and moderate surface epithelial hyperplasia by 12 wk (Fig $2 \mathrm{C}$ and $\mathrm{D}$ ). Mice expressing active KRAS had far more striking changes to the tissue over time (Fig 2E-H). To quantify the effects of Hp infection in this model, a blinded analysis was performed to assess inflammation, oxyntic atrophy (loss of parietal cells), and surface epithelial hyperplasia in active KRAS-expressing mice (Fig $3 A-C)$.

KRAS expression caused changes to the corpus epithelium that were apparent within 2 wk, with a moderate degree of inflammation,

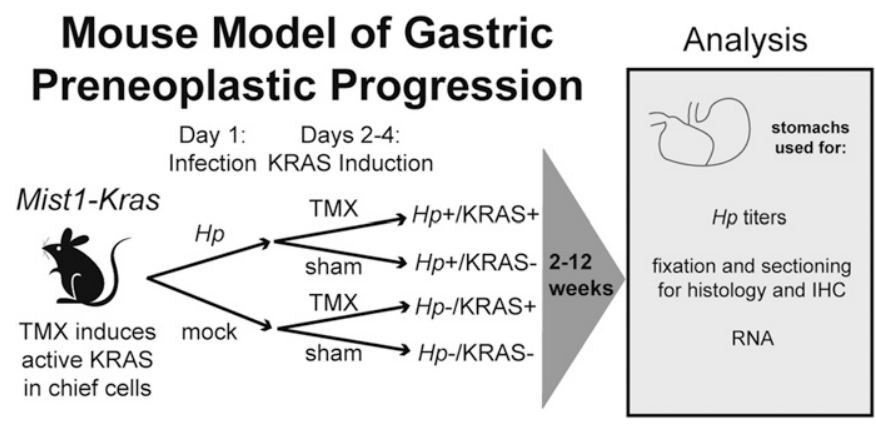

Figure 1. Mist1-Kras mice were used to assess whether and how Hp infection alters gastric preneoplastic progression.

On day one, mice are infected with $\mathrm{H}$. pylori $(\mathrm{Hp})$ by oral gavage, or mock-infected. On days two through four, mice receive daily injections with tamoxifen (TMX) to induce a constitutively active Kras allele (G12D) in the chief cells (Mist1expressing) of the stomach. After 2, 6, or $12 \mathrm{wk}$, mice are humanely euthanized and the glandular stomach (excluding forestomach region) is assessed as indicated.

surface epithelial hyperplasia, and some loss of parietal cells. These changes were slightly more severe in a subset of $\mathrm{Hp}+$ / KRAS+ mice, but overall there were no significant histological differences between $\mathrm{Hp}-/$ KRAS + and $\mathrm{Hp}+/$ KRAS + mice at this early time point (Fig 2E and G). By 6 wk, each of these parameters became more severe, and notably, parietal cell loss was significantly greater in $\mathrm{Hp}+$ / KRAS + mice compared with Hp-/KRAS + mice (Fig 3A). By 12 wk, $\mathrm{Hp}-/$ KRAS + mice had mucinous cells, in line with previous observations (Choi et al, 2016) (Fig 2F). Hp+/KRAS+ mice looked different from $\mathrm{Hp}$-/KRAS+ mice, with loss of normal basal polarity of epithelial cells, and gland architecture that was severely disrupted, including forked or star-shaped gland structure indicative of extensive branching and disorganized maturation (Fig 2G). As well, these mice had hyperchromatic nuclei with variations in nuclear size, which can indicate dysplasia. Moreover, at 12 wk Hp+/KRAS+ mice had significantly increased inflammation, parietal cell loss and surface epithelial hyperplasia compared with $\mathrm{Hp}-$ / KRAS+ mice (Fig $3 A-C$ ). Finally, the overall histology score (histological activity index [HAl]), which sums the above scores along with scores for other parameters like epithelial defects and hyalinosis (Fig S1) and which thus indicates the degree of overall immunopathology (Rogers, 2012), was significantly increased in $\mathrm{Hp}+/$ KRAS + mice compared with $\mathrm{Hp}$-/KRAS+ mice at both 6 and 12 wk (Fig 3D). Thus, concomitant $\mathrm{Hp}$ infection and active KRAS expression in the corpus leads to histopathological changes to the tissue within 6 wk that become more severe by 12 wk.

The striking inflammation seen in $\mathrm{Hp}+/ \mathrm{KRAS}+$ mice compared with $\mathrm{Hp}+$ / KRAS- mice might be expected to eliminate $\mathrm{Hp}$ infection. However, Hp was recovered from most KRAS+ mice by stomach culturing (Fig 3E), demonstrating that the bacterium could to some extent withstand the severe inflammation of the preneoplastic stomach. At 2 wk, Hp titers did not differ between $\mathrm{Hp}+/$ KRAS-and $\mathrm{Hp}+/$ KRAS + mice, suggesting that the early histopathological changes did not impact bacterial colonization. In sham-induced (KRAS-) mice, $\mathrm{Hp}$ titers were similar at 6 and $12 \mathrm{wk}$, and in both cases were lower than at 2 wk, likely because of the onset of adaptive immunity to control the infection. However, in $\mathrm{Hp}+/ \mathrm{KRAS}+$ mice, the contraction of 
踽 Life Science Alliance
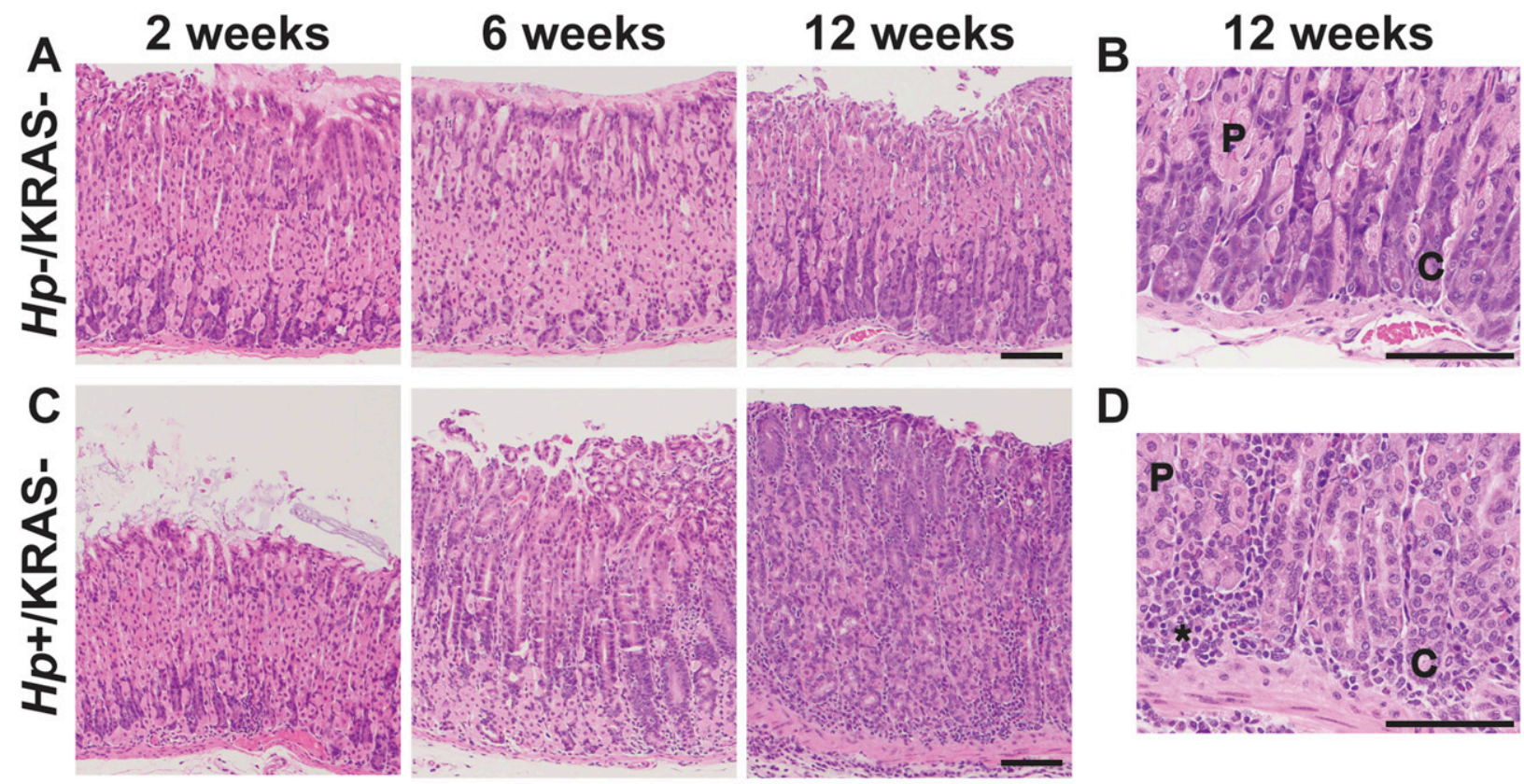

D
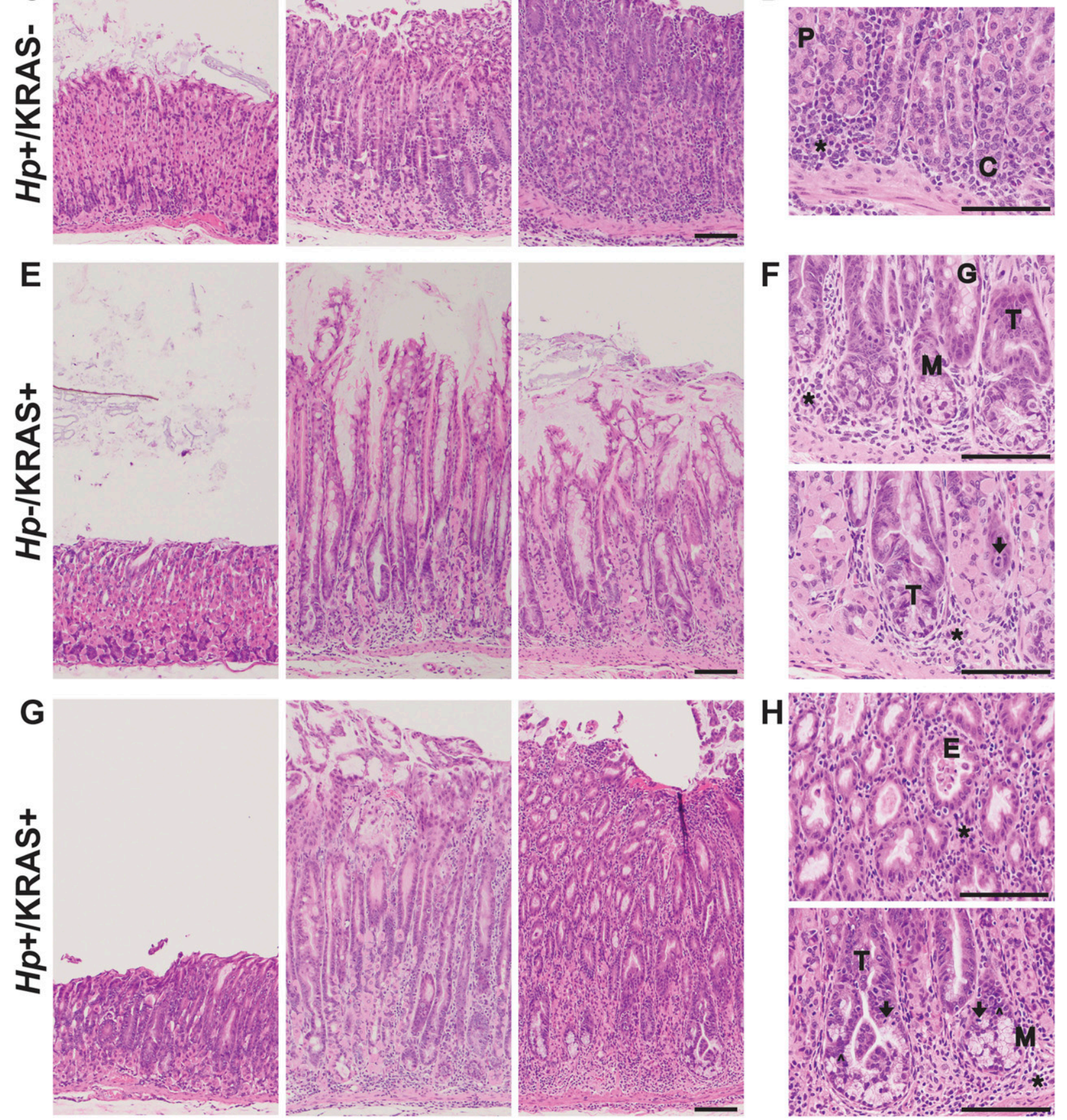

Figure 2. Concomitant $\mathrm{Hp}$ infection and active KRAS expression changes tissue histology.

Formalin-fixed, paraffin-embedded corpus tissue was stained with hematoxylin \& eosin and examined with a Nikon Eclipse 50i microscope using 10x and 40x objectives. Images were taken with an Olympus DP27 camera using cellSens 2.3 acquisition software (Olympus). (A, B, C, D, E, F, G, H) Shown are representative images from Hp-/KRAS- (A, B), Hp+/KRAS- (C, D), Hp-/KRAS+ (E, F), and Hp+/KRAS + (G, H) mice ( $\mathrm{n}=10-16$ per group) after 2, 6, or 12 wk as indicated. Scale bars, $100 \mu \mathrm{m} .(\mathbf{B}, \mathbf{D}, \mathbf{F}, \mathrm{H})$ 
the $\mathrm{Hp}$ population was greater, with $\mathrm{Hp}$ recovered from only 10 out of 12 animals at 6 wk and 10 out of 13 animals at 12 wk. Hp could be detected within glands by immunofluorescence microscopy (Fig S2). No differences in titer or overall histology score were observed between male and female mice. Interestingly, stomach $\mathrm{Hp}$ loads were not correlated with histology scores (Fig 3F). We therefore hypothesized that the host inflammatory response to $\mathrm{Hp}$ infection might contribute to $\mathrm{Hp}$-dependent tissue changes.

\section{Hp infection increases and alters KRAS-driven inflammation}

Activated KRAS expression itself elicits inflammation: by $12 \mathrm{wk}$, the median corpus inflammation score in $\mathrm{Hp}$-/KRAS+ mice was two (Fig 3B), denoting coalescing aggregates of inflammatory cells in the submucosa and/or mucosa (Rogers, 2012). In this histological evaluation, the addition of $\mathrm{Hp}$ significantly increased inflammation by 12 wk $(P<0.01)$, with the median score rising to three (denoting organized immune cell nodules in the submucosa and/or mucosa). To characterize the nature of the inflammation, gene expression changes at 12 wk were assessed with a NanoString Mouse Immunology panel (Fig 4 and Table S1). Transcripts of Cd45, a panimmune cell marker, were significantly increased in $\mathrm{Hp}+$ /KRASmice and especially in $\mathrm{Hp}+/ \mathrm{KRAS}+$ mice compared with $\mathrm{Hp}$ - mice (Fig S3), suggesting greater numbers of immune cells in infected mice. Of the 561 genes in the panel, 60 had no detectable expression among any mice $(n=25)$ and were excluded from subsequent analysis. Hierarchical clustering was performed on the remaining 501 genes and revealed distinct clustering of the treatment groups (Fig 4A). All $\mathrm{Hp}+$ mice clustered separately from $\mathrm{Hp}$ - mice, demonstrating that infection had the greatest impact on gene expression. Within both the $\mathrm{Hp}+$ and the $\mathrm{Hp}$ - cluster, KRAS+ mice clustered separately from KRAS- mice, suggesting that active KRAS expression also impacted inflammatory gene expression, although to a lesser extent than $\mathrm{Hp}$ infection did.

Next we assessed gene expression patterns in the different mouse groups. Compared with $\mathrm{Hp}-/$ KRAS + mice, $\mathrm{Hp}+/$ KRAS + mice had 235 significantly differentially expressed genes $\left(P_{\text {adjusted }}<0.05\right)$ (Fig 4B). Several of the most highly up-regulated genes, including Cd3d, Cd3e, Cd4, Cd8a, Gzma, Ctla4, Icos, and Cd6, implicated a strong T-cell response, in accordance with previous studies in humans and naive animal models (Eaton et al, 2001; Ernst et al, 1997). Likewise, compared with $\mathrm{Hp}$-/KRAS- mice, $\mathrm{Hp}+$ /KRAS- mice had 177 differentially expressed genes, with $\mathrm{Cd} 3 d, \mathrm{Cd} 3 e, \mathrm{Cd} 4, \mathrm{Cd} 8 \mathrm{a}$, Gzma, Ctla4, Icos, and Cd6 once again highly significantly differentially expressed (Fig 4C). Thus, many of the gene expression differences seen in $\mathrm{Hp}+/ \mathrm{KRAS}+$ mice versus $\mathrm{Hp}$-/KRAS+ mice are likely reflective of a general pattern of $\mathrm{Hp}$-mediated inflammation that is independent of the metaplastic state of the tissue. However, we identified a unique inflammatory gene signature in $\mathrm{Hp}+$ /KRAS+ mice (Fig 4D), demonstrating that the inflammation observed in this group is not only of a greater magnitude than in the other groups but also of a different nature. We identified 46 genes whose expression (normalized to $\mathrm{Hp}$-/KRAS- mice) was $>2$-fold increased or decreased in $\mathrm{Hp}+$ / KRAS + mice, but $<1.5$-fold increased or decreased in $\mathrm{Hp}+$ / KRAS- and $\mathrm{Hp}$ - / KRAS + mice. Many of these genes implicated T cells (Ccr6, Cd27, Cd53, Cxcl11, Foxp3, Gata3, Il12b, Pdcd1lg2 [PD-L2], Tigit, and Tnfsf18 up-regulated; Il17re down-regulated) and macrophages (CCl3, Csf1r, Emr1 [F4/80], Il1a, and Irf5 up-regulated). As well, most markers of T-cell exhaustion (Blackburn et al, 2009; Saeidi et al, 2018) were only strongly expressed in $\mathrm{Hp}+$ /KRAS + mice (Fig S4). Thus, even though both $\mathrm{Hp}+/$ KRAS + mice and $\mathrm{Hp}+$ /KRASmice had significant up-regulation of T-cell-related genes compared with their $\mathrm{Hp}$ - counterparts, the addition of active KRAS may impact the nature of T-cell polarization and function.

In animal models, immune pressure due to chronic $\mathrm{Hp}$ infection results in loss of function of the Hp type IV secretion system (T4SS) (Barrozo et al, 2013). Hp strains isolated from long-term experimental infections of C57BL/ 6 mice (but not Rag1 mice deficient in adaptive immune responses), gerbils and monkeys lose their ability to elicit IL-8 secretion by gastric epithelial cells in vitro (Barrozo et $\mathrm{al}, 2013$ ). In line with these observations, we found that $50 \%$ of $\mathrm{Hp}$ strains isolated from 12+ wk infections of KRAS- mice had lost their T4SS activity (Fig S5). Surprisingly, Hp strains isolated from KRAS+ mice were no more likely to lose their T4SS activity, despite the severe inflammation seen in these animals.

\section{$\mathrm{Hp}+$ /KRAS+ mice have T cells throughout the lamina propria and fewer M2 macrophages}

To detect immune cell subsets in the corpus of $\mathrm{Hp}-/$ KRAS+ versus $\mathrm{Hp}+$ / KRAS+ mice at $12 \mathrm{wk}$, we performed multiplex fluorescent immunohistochemistry (IHC) with the following markers: for T cells, CD3, CD4, CD8 $\alpha$, FOXP3 (regulatory T cell marker), and PD-1 (T-cell exhaustion marker); for macrophages, F4/80 and the polarization markers MHC class II (M1 macrophages) and CD163 (M2 macrophages) (Fig 5). HALO software was used to detect and enumerate immune cell subsets (Fig S6). In $\mathrm{Hp}-$ I KRAS+ mice we detected moderate numbers of $\mathrm{CD}^{+} \mathrm{T}$ cells, most of which were $\mathrm{CD}^{+}$, and a few of which were CD8 $\alpha^{+}$(Figs $5 \mathrm{~A}$ and S6A). $\mathrm{Hp}+/ \mathrm{KRAS}+$ mice had significantly more $\mathrm{CD}^{+} \mathrm{T}$ cells, but the proportion of $\mathrm{CD}^{+}$versus $\mathrm{CD} 8 \alpha^{+}$cells was similar, with more $\mathrm{CD}^{+}$than $\mathrm{CD} 8 \alpha^{+}$cells. Interestingly, most of the $\mathrm{CD}^{+}$cells in $\mathrm{Hp}$-/KRAS+ mice expressed FOXP3 and PD-1 (Fig $5 B$ ), suggesting they may be activated regulatory $T$ cells (Lowther et al, 2016). In Hp+/KRAS+ mice, there were significantly more FOXP3+ cells (Fig S6A), some of which were PD-1 double positive (Fig 5B). However, many $\mathrm{CD}^{+}$cells did not express either of these markers, suggesting they may be different T-cell subsets than are found in Hp-/KRAS+ mice, and/or NK cells. Cell localization was also different between treatment groups: in $\mathrm{Hp}$-/KRAS+ mice, most T cells were located at the base of the glands, whereas in $\mathrm{Hp}+$ /KRAS + mice, $\mathrm{T}$ cells were located throughout the glands. Finally, both groups of mice had $\mathrm{F} 4 / 80^{+}$cells throughout the lamina propria (Figs 5C and S6B), suggesting presence of macrophages or eosinophils (McGarry \& Stewart, 1991). We previously found that M2 macrophages promoted SPEM progression in mice and were associated with human SPEM and IM (Petersen et al, 2014). In Hp-/KRAS+ mice, some F4/ $80^{+}$cells were dual-positive for the M2 polarization marker CD163, in line with previous findings (Choi et al, 2016), and some were dual-positive for

Examples of the following morphological features are designated in the higher magnification images in (B, D, F, H): chief cells (C); glandular ectasia (E); goblet-like cell morphology (G); hyperchromatic nuclei (carets); immune cells (asterisks); mitotic figures (arrows); mucus (M); parietal cells (P); tortuous glands (T). 
B

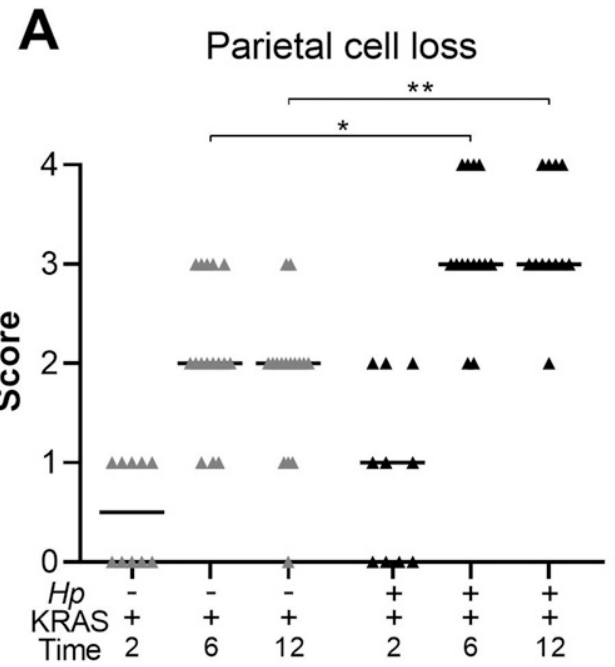

Inflammation

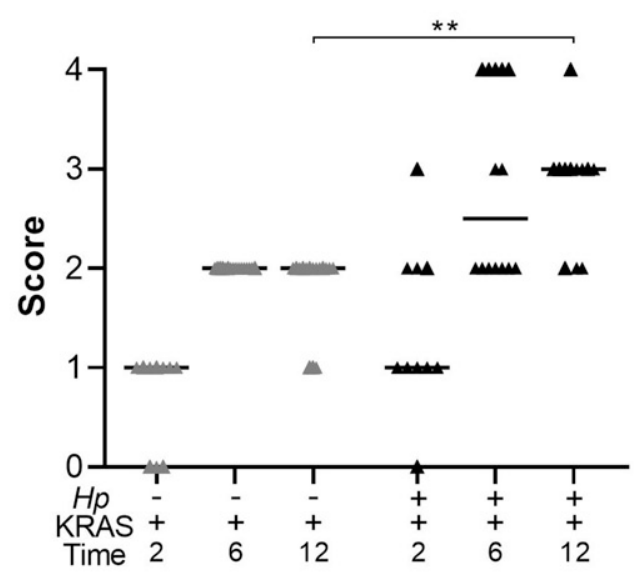

D
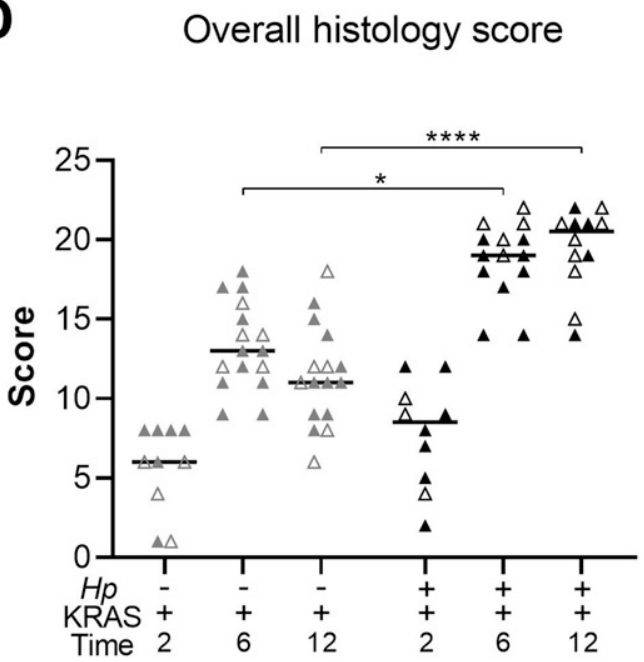

$\mathbf{F}$

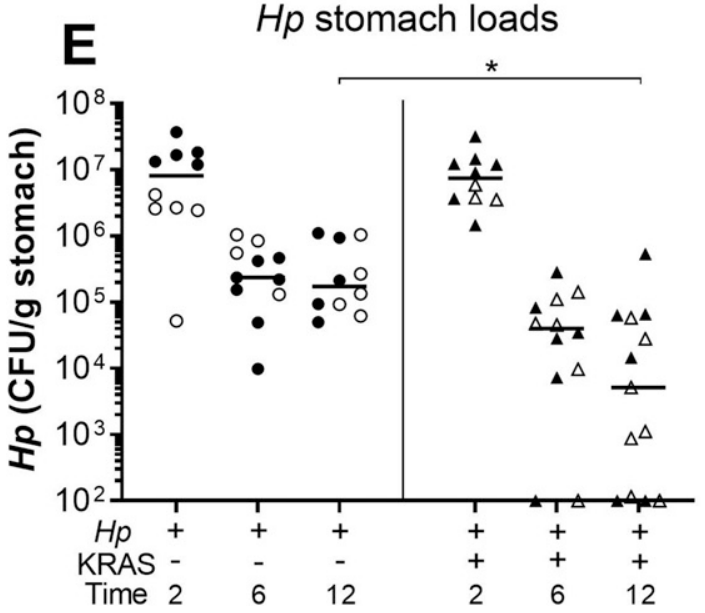

Histology vs. stomach loads

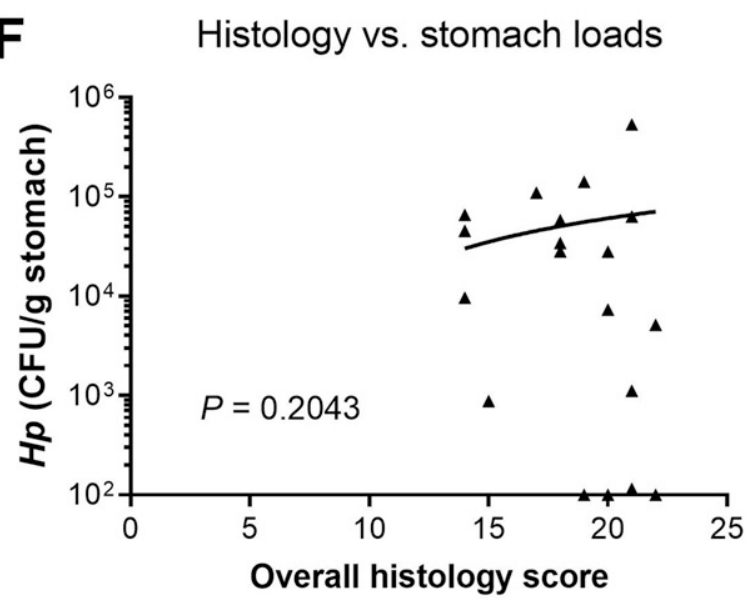

Figure 3. Hp+/KRAS+ mice have severe gastric immunopathology marked by inflammation, loss of parietal cells, and surface epithelial hyperplasia. Stomachs from $n=10-16$ mice per group were evaluated for tissue pathology and bacterial colonization. (A, B, C, D) Hematoxylin-and-eosin-stained corpus tissue was assessed for parietal cell loss (oxyntic atrophy) (A), inflammation (B), surface epithelial hyperplasia (C), and the composite histological activity index (D) in a blinded fashion using the Rogers criteria (Rogers, 2012). (E) Hp loads were assessed by quantitative culture; mice with no detectable colonization were plotted at the limit of detection. (F) Comparison of Hp loads and overall histology score (from D) from the same mouse at 6 or 12 wk. Significance was assessed by Spearman correlation. Data are combined from $\mathrm{N}=2$ independent mouse experiments per time point. Data points represent actual values for each individual mouse and bars indicate median values. 

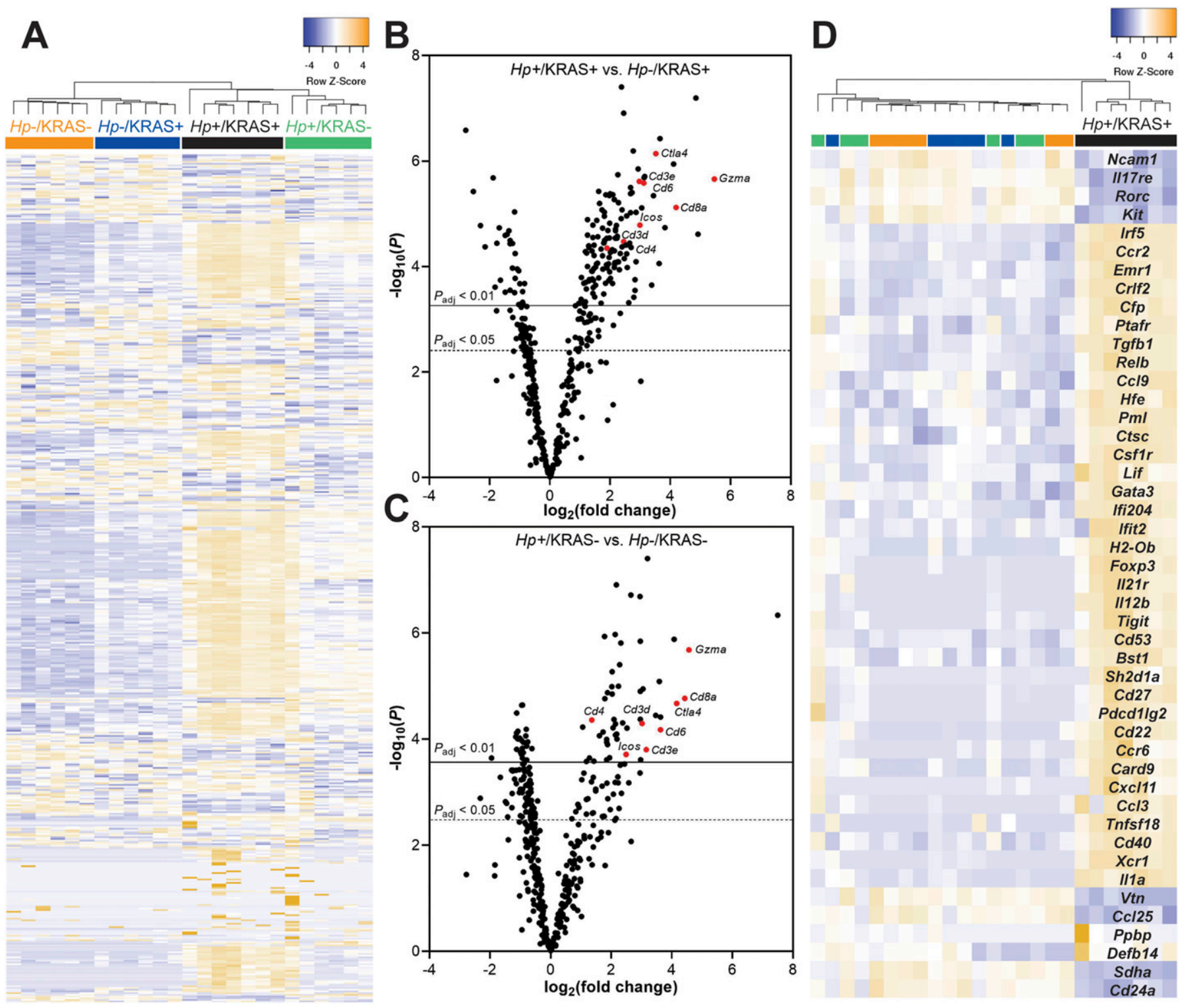

Figure 4. A unique inflammatory gene signature exists in $\mathrm{Hp}+/ \mathrm{KRAS}+$ mice at $12 \mathrm{wk}$.

RNA was extracted from stomach sections from $\mathrm{Hp}+/-$, KRAS $+/$ - mice at 12 wk and immune-related gene expression was detected with the NanoString $n C$ Counter Mouse Immunology Panel. (A) Expression of 501 genes is shown. Colored bars denote different treatment groups. (B, C) Volcano plots show the fold change and P-values of all genes in the panel, for $\mathrm{Hp}+/$ KRAS + mice versus $\mathrm{Hp}$-/KRAS+ mice (B) and $\mathrm{Hp}+/$ KRAS- mice versus $\mathrm{Hp}$-/KRAS- mice (C). A subset of T cell-related genes is shown in red and labeled. Lines show genes meeting the threshold for significance after correction with the Benjamini-Yekutieli procedure. (D) Expression of 46 genes (see text) that were uniquely differentially expressed in $\mathrm{Hp}+/$ KRAS + mice versus all other groups is shown. The dendrograms at the top of the heat maps were produced by hierarchical clustering of gene expression. Data comes from $N=1$ NanoString experiment with $n=6-7$ mice per group from $N=2$ independent mouse experiments.

the M1 polarization marker MHC class II. Hp+/KRAS+ mice had similar numbers of $\mathrm{F} 4 / 80^{+} / \mathrm{MHC}$ class $\mathrm{II}^{+}$cells present, but significantly fewer $\mathrm{F} 4 /$ $80^{+} / \mathrm{CD} 63^{+}$cells (Fig S6B), suggesting altered macrophage polarization; most CD163 signal was observed in the gland lumen, likely nonspecific staining due to mucus binding. These IHC experiments confirm our gene expression-based findings that inflammation in $\mathrm{Hp}+/$ KRAS+ mice is not only more severe than in $\mathrm{Hp}$-/KRAS+ mice but is also altered in nature.

\section{Hp infection alters metaplasia marker expression}

We wondered whether the changes in tissue histology observed in $\mathrm{Hp}+$ /KRAS + mice (Fig 2) reflected changes to the nature of metaplasia in these mice. To detect differences in hyperplasia, metaplasia, and cell proliferation in corpus tissue from $\mathrm{Hp}+/$ KRAS+ versus $\mathrm{Hp}$-/KRAS+ mice over time (Fig $6 \mathrm{~A}-\mathrm{C}$ ), we used conjugated 

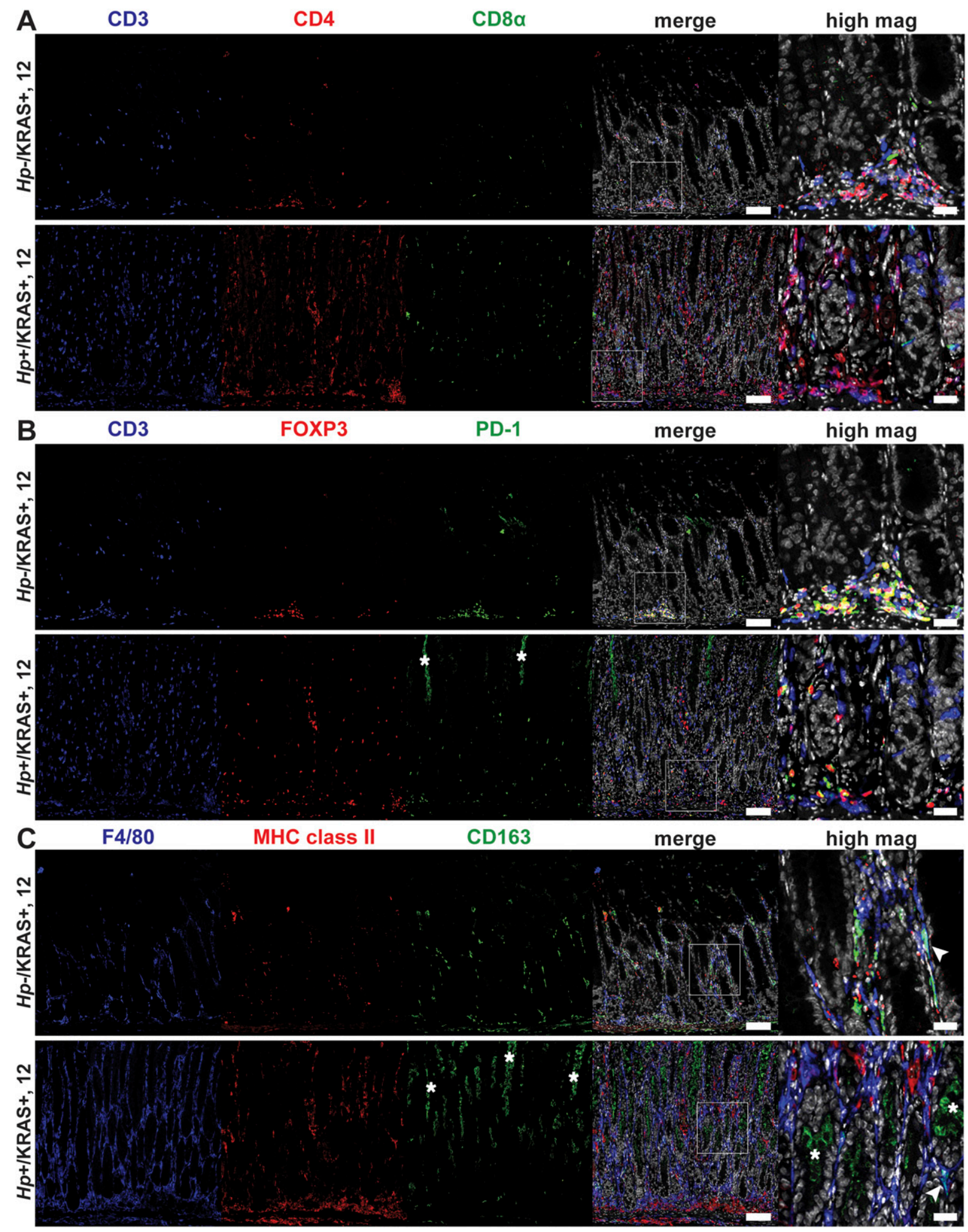

Figure 5. Multiplex immunohistochemistry demonstrates more T cells and fewer M2 macrophages in $\mathrm{Hp}+/ \mathrm{KRAS}+$ mice.

Corpus tissue from $\mathrm{Hp}$-/KRAS+ and Hp+/KRAS+ mice obtained after 12 wk was assessed by multiplex immunohistochemistry. Images were acquired with the Vectra Polaris Quantitative Pathology Imaging System (Akoya Biosciences) with a 20x objective. Phenochart was used to select multispectral image tiles, which were spectrally unmixed with Akoya inForm software and analyzed in HALO (Indica Labs). Representative images are shown and white boxes denote regions shown at higher magnification. (A) CD3 suggests T cells, CD4 indicates helper T cells, and CD8 $\alpha$ indicates cytotoxic T cells. (B) CD3 suggests T cells, FOXP3 indicates regulatory T cells, and PD-1 is a marker of exhausted T cells. (C) F4/80 suggests macrophages, MHC class II indicates M1 macrophages, CD163 indicates M2 macrophages, and arrowheads indicate 
lectin from Ulex europaeus (UEA-I), which binds $\alpha$-L-fucose, to detect foveolar (pit cell) hyperplasia; conjugated Griffonia simplicifolia lectin II (GS-II), which binds $\alpha$ - or $\beta$-linked N-acetylD-glucosamine, to detect mucous neck cells and SPEM cells; anti-CD44V10 (orthologous to human CD44V9, referred to herein as "CD44V") to detect SPEM cells (Radyk et al, 2018); anti-TFF3 and antiMUC2 to detect IM (goblet) cells (Merchant, 2005) (verified by staining of mouse intestine as shown in Fig S7); and anti-KI-67 to detect proliferating cells. We assessed differences through quantitative and semi-quantitative analysis of three to five images per mouse (Fig 6D-H). No difference was observed in UEA-I staining among the treatment groups (Fig S8), suggesting that $\mathrm{Hp}$ infection did not impact foveolar hyperplasia development in this model. In $\mathrm{Hp}$-/KRAS+ mice, GS-II staining was observed at the base of the glands at 6 wk, co-localizing with CD44V, demonstrating SPEM (Fig 6A, $D$, and $E$ ). As well, most mice had robust, cell-associated TFF3 staining (Fig $6 \mathrm{~A}$ and F) and a low degree of MUC2 staining (Fig 6B and G), suggestive of early IM. At 12 wk, CD44V and GS-II staining was reduced, TFF3 staining remained robust, and the percentage of $\mathrm{MUC2}^{+}$glands increased, suggesting a transition from SPEM to IM in these mice, consistent with previous findings (Choi et al, 2016). In Hp+/KRAS+ mice, GS- II and MUC2 staining patterns were similar, with GS-II decreasing and MUC2 increasing between 6 and 12 wk (Fig 6A, B, D, and $\mathrm{G})$. However, CD44v and TFF3 exhibited a different pattern. At 6 wk, $\mathrm{Hp}+$ / KRAS+ mice had greater CD44V staining and less TFF3 staining than $\mathrm{Hp}-/ \mathrm{KRAS}+$ mice (Fig 6A, E, and F). By $12 \mathrm{wk}, \mathrm{CD} 44 \mathrm{~V}$ staining waned somewhat but remained higher than in $\mathrm{Hp}-/$ KRAS+ mice, and TFF3 staining further diminished compared with $\mathrm{Hp}$-/KRAS+ mice. Taken together, these results demonstrate that $\mathrm{Hp}$ infection alters the kinetics of metaplasia development in KRAS+ mice. Metaplasia marker expression was not detected in KRAS- mice (Fig S9). Of note, no differences in immunostaining patterns or quantification were observed in KRAS + mice at 2 wk (Fig S10), suggesting that $\mathrm{Hp}$-driven metaplastic changes take longer than 2 wk to become apparent. Finally, we assessed expression of phospho-ERK1/2, which is a downstream target of KRAS signaling (Choi et al, 2016), in + / - Hp, + / Kras mice at 12 wk (Fig S11). Most signal in KRASmice with or without $\mathrm{Hp}$ infection was nonspecific, with only one or two positive cells per field of view. In contrast, KRAS + mice had robust phospho-ERK1/2 signal that did not increase with $\mathrm{HP}$ infection. Thus, the altered metaplasia observed in $\mathrm{Hp}+/$ KRAS+ mice is not due to enhanced KRAS activity.

We observed mitotic figures in KRAS + mice at 12 wk (Fig $2 \mathrm{~F}$ and $\mathrm{H}$ ), suggesting increased cell division. Previously, patients with IM were found to have significantly increased cellular proliferation (assessed by KI-67 staining) in biopsy tissue compared with healthy controls and patients with chronic active gastritis (Erkan et al, 2012). Here, we found substantially more $\mathrm{KI}-67+$ nuclei in corpus tissue of $\mathrm{Hp}+$ / KRAS + mice than $\mathrm{Hp}-/$ KRAS + mice at both 6 and 12 wk (Fig 6C and $\mathrm{H}$ ). Most $\mathrm{KI}-67+$ cells were found within the glandular epithelial compartment, not in the lamina propria, and interestingly, the localization of KI-67+ cells was altered in KRAS+ mice. In KRAS- mice, proliferating cells were found in the middle of the glands, where gastric stem cells are found (Fig S9B). We observed that KI-67+ cells localized toward the base of the glands in $\mathrm{Hp}-/$ KRAS + mice (Fig 6C). In $\mathrm{Hp}+$ /KRAS+ mice, $\mathrm{KI}-67$ cells were abundant toward the base of the glands and higher up into the middle of the glands. In both groups of mice, some KI-67+ nuclei were found in GS-II+ cells at the base of the glands, suggesting proliferation of SPEM cells. However, in $\mathrm{Hp}+$ /KRAS+ mice, most KI-67+ nuclei were found above GS-II+ cells, suggesting proliferation of additional cell types beyond those with a SPEM phenotype.

\section{Hp infection increases dysplasia and cancer-associated gene expression}

Overexpression of the calcium signal transducer TROP2 has been implicated in a variety of cancers (Shvartsur \& Bonavida, 2015), including gastric cancer, where it is associated with worse outcomes (Muhlmann et al, 2009). Notably, TROP2 expression was recently identified as a strong indicator of the transition from incomplete IM to gastric dysplasia in Mist1-Kras mice and in human samples (Riera et al, 2020). We observed TROP2+ corpus glands by immunofluorescence microscopy at 6 and 12 wk (Figs 7A and S12). Quantitation using collagen VI as a gland segmentation marker revealed that $\mathrm{Hp}$-/KRAS+ mice had TROP2 expression in $0-3.6 \%$ of glands at 6 wk, and $0-4.9 \%$ of glands at $12 \mathrm{wk}$ (Figs 7B and S12). $\mathrm{Hp}+$ / KRAS+ mice had similar TROP2 expression at $6 \mathrm{wk}(0.5-2.5 \%$ of glands), but at 12 wk had significantly more TROP2+ glands (1.5-9.1\%, P< 0.05). Thus, the addition of $\mathrm{Hp}$ significantly increased the percentage of TROP2+ glands in the corpus at $12 \mathrm{wk}$. In all mice, most regions of TROP2 staining co-localized with $\mathrm{KI}-67$ staining, suggesting proliferation of dysplastic glands. Only a few TROP2+ regions did not harbor KI-67+ cells (Fig 7A, asterisk). However, the association between TROP2 and KI-67 was greatest in $\mathrm{Hp}+$ /KRAS+ mice at $12 \mathrm{wk}$, where a median of $86 \%$ of TROP2+ glands or gland fragments were $\mathrm{KI}-67+(P<0.01)$ (Fig $7 C$ ), suggesting that $\mathrm{Hp}$ infection increases the proliferation of dysplastic glands.

We mined our NanoString gene expression data (Fig 4A) and identified 49 genes implicated in the development of gastrointestinal cancers (Alpizar-Alpizar et al, 2012; Lee et al, 2012; Jin et al, 2015; Huang et al, 2018; Min et al, 2019; Molina-Castro et al, 2020). Hierarchical clustering analysis showed that as with the overall panel, $\mathrm{Hp}$ infection status had the greatest impact on expression of this subset of genes at $12 \mathrm{wk}$, and that active KRAS expression also impacted gene expression, although to a lesser extent than $\mathrm{HP}$ infection status did (Fig 7D). However, some genes, such as Jak2, Notch2, and Runx1, were up-regulated in KRAS+ mice regardless of infection status. Finally, metaplastic and dysplastic organoids generated from $\mathrm{Hp}-/$ KRAS + mice at 12 and 16 wk after active KRAS induction, respectively, were previously found to have unique phenotypes and gene expression signatures (Min et al, 2019). Seven of these genes were found in our panel (Fig 7D, denoted with \#). Expression of the metaplasia-associated gene Clu was strongly upregulated in KRAS+ mice, but the metaplasia-associated gene Ly86 was only strongly expressed in $\mathrm{Hp}+$ /KRAS + mice. Of the dysplasia-

$\mathrm{F} 4 / 80^{+} / \mathrm{CD}_{163}{ }^{+}$cells. Scale bars for low magnification ("merge”) images, $100 \mu \mathrm{m}$; for high magnification images, $25 \mu \mathrm{m}$. Data are from $\mathrm{N}=1 \mathrm{multiplex}$ immunohistochemistry experiment, with $n=7$ mice per group from $\mathrm{N}=2$ independent mouse experiments. (B, C) Asterisks denote examples of nonspecific staining as determined by luminal location, lack of DAPI signal and lack of co-localization with relevant markers (B, CD3, and C, F4/80). 


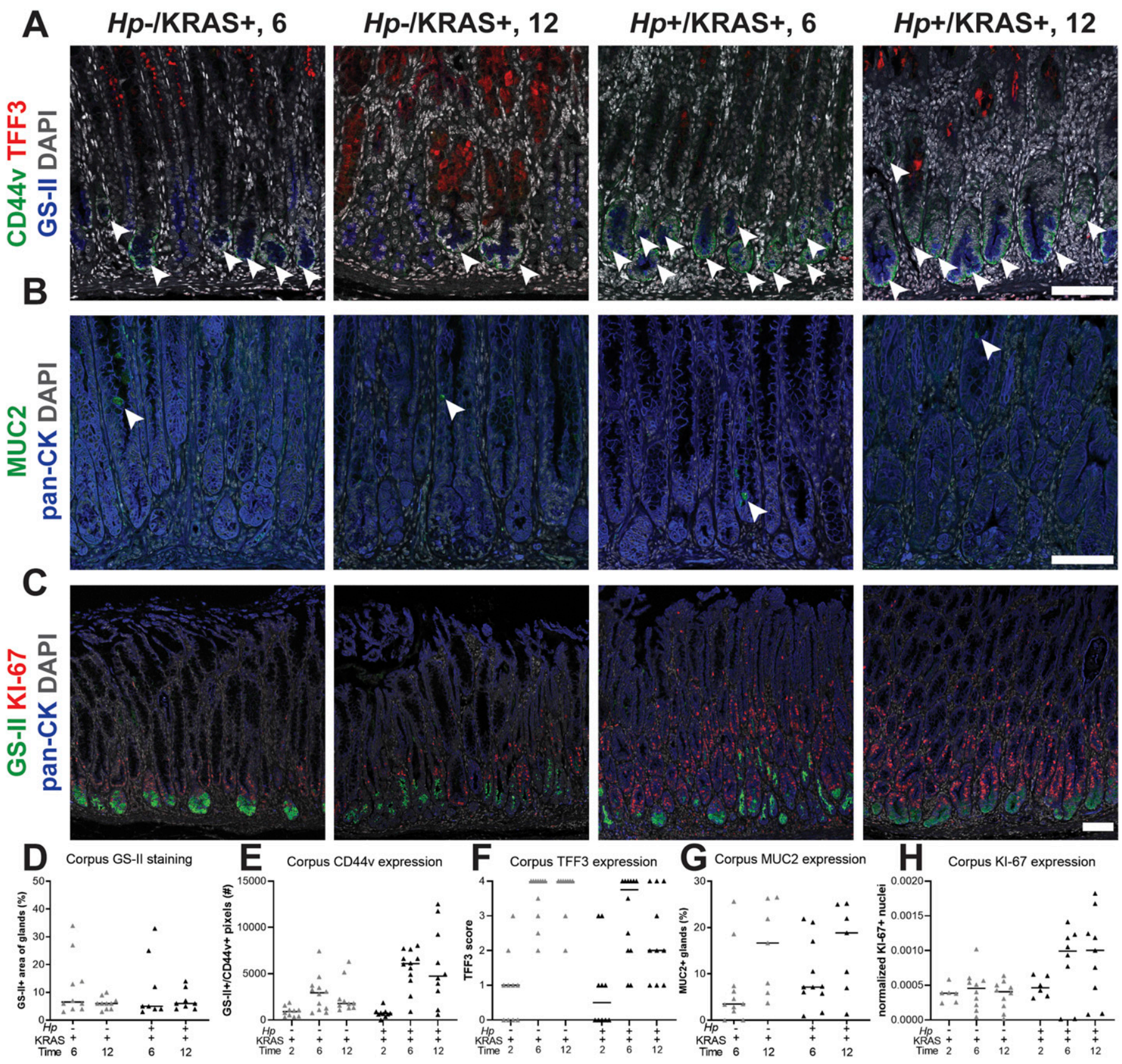

Figure 6. The kinetics and molecular nature of metaplasia development are altered in $\mathrm{Hp}+/ \mathrm{KRAS}+$ mice.

Corpus tissue from $\mathrm{Hp}-/ \mathrm{KRAS}+$ and $\mathrm{Hp}+/ \mathrm{KRAS}+$ mice obtained after 2, 6, or $12 \mathrm{wk}(\mathrm{N}=2$ independent mouse experiments per time point and $\mathrm{n}=6-12 \mathrm{mice}$ per group) was assessed for metaplasia via immunofluorescence microscopy. (A, B, C) Images were taken with a Zeiss LSM 780 confocal microscope using 10× and 20× objectives and analyzed with Zen and Fiji software. Representative images are shown and scale bars are $100 \mu \mathrm{m}$. (A) Stomachs were stained with antibodies against CD44V (green; arrowheads) and TFF3 (red), the lectin GS-II (blue), and DAPI (grey) in N = 3 staining experiments. (B) Stomachs were stained with antibodies against MUC2 (green; arrowheads) and pan-cytokeratin (blue) and DAPI (grey) in N = 2 staining experiments. (C) Stomachs were stained with antibodies against KI-67 (red) and pan-cytokeratin (blue), the lectin GS-II (green) and DAPI (grey) in N $=3$ experiments. (D, E, F, G, H) Three to five representative images per mouse were quantitatively or semi-quantitatively assessed and the median value for each mouse is plotted. Bars on the graphs indicate the median value for each mouse group. (D) The percentage of cytokeratinpositive epithelial tissue that was dual-positive for GS-II staining was detected. (E) The number of GS-II+ $/$ DD44V ${ }^{+}$pixels per image was quantified. (F) TFF3 staining was semi-quantitatively scored in a blinded fashion. Nonspecific staining was not included in the score (see Fig S9). (G) The percentage of MUC2 ${ }^{+}$glands was determined by counting. (H) $\mathrm{KI}^{-67^{+}} / \mathrm{DAPI}^{+}$nuclei were enumerated and normalized to the DAPI content (total number of $\mathrm{DAPI}^{+}$pixels) of each image.

associated genes, Tubb5 was elevated in $\mathrm{Hp}+$ mice, Gapdh was elevated in KRAS+ mice, and Eef1g was not differentially expressed among treatment groups. Finally, Cd44 and Tgfb1 were previously found in both metaplastic and dysplastic organoids (Min et al, 2019) and in our study were strongly elevated in $\mathrm{Hp}+$ / KRAS + mice at $12 \mathrm{wk}$ relative to the other mouse groups. Thus, gene expression in $\mathrm{Hp}+1$ KRAS+ whole stomachs at $12 \mathrm{wk}$ is distinct from $\mathrm{Hp}-/$ KRAS+ organoids generated at either 12 or 16 wk, further supporting the 
A

Hp-/KRAS+, 6

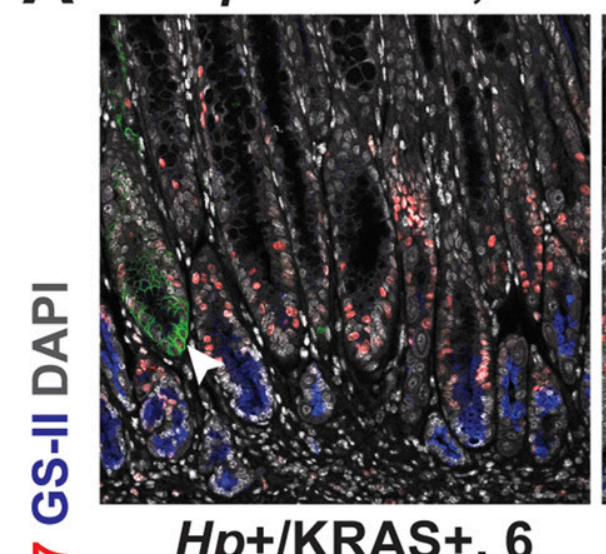

Hp-/KRAS+, 12

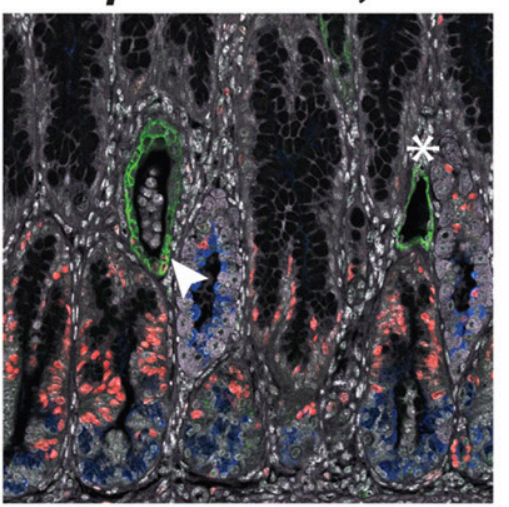

D

Hp+/KRAS+, 12
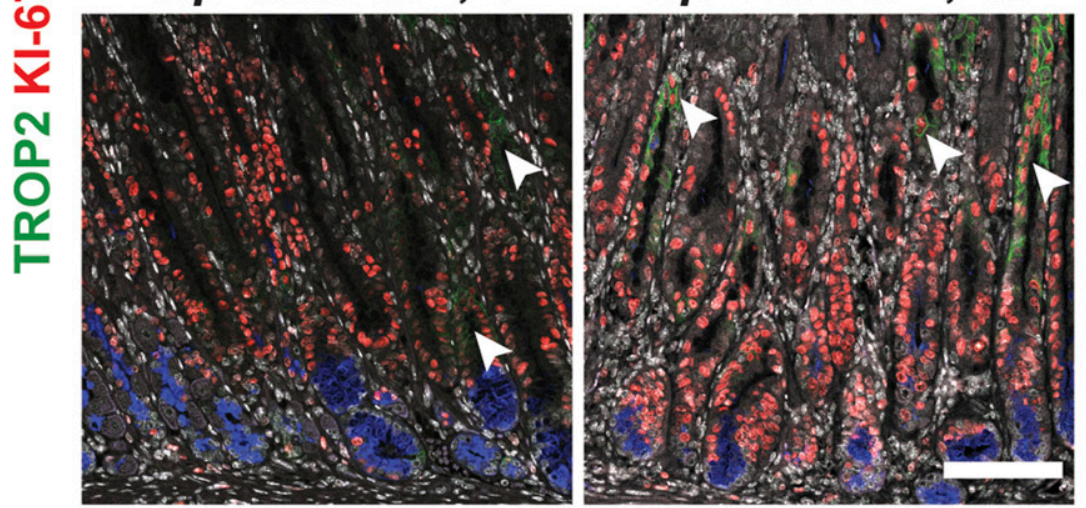

B
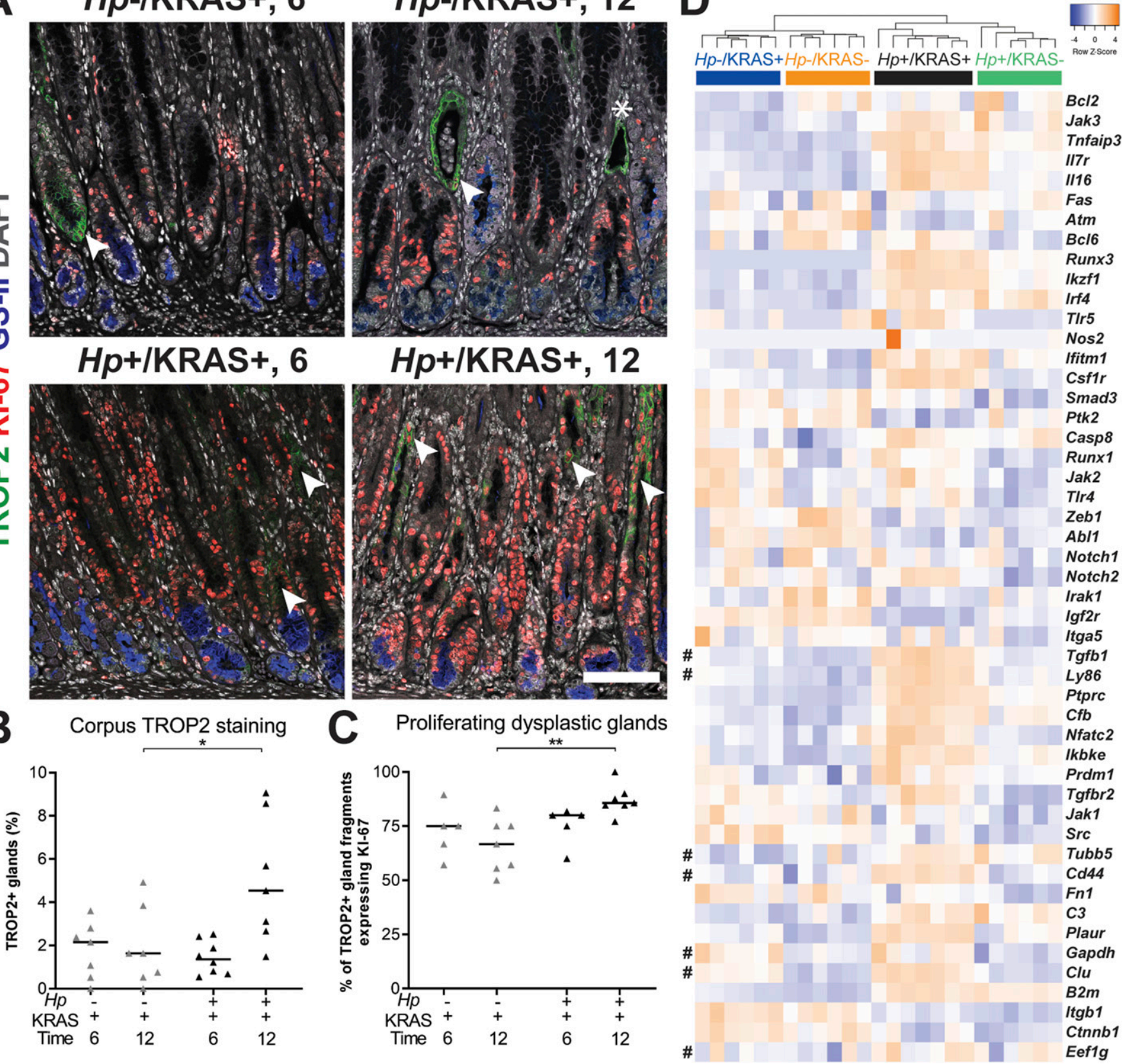

Figure 7. Hp infection increases dysplasia and cancer gene expression in KRAS+ mice.

(A, B, C, D) Stomachs from $\mathrm{Hp}-/$ KRAS+ and $\mathrm{Hp}+/$ KRAS + mice were assessed through immunofluorescence microscopy (A, B, C) and gene expression analysis (D). (A, B, C) Corpus tissue from Hp-/KRAS+ and $\mathrm{Hp}+/ \mathrm{KRAS}+$ mice obtained after 6 or $12 \mathrm{wk}(\mathrm{N}=2$ independent mouse experiments per time point and $\mathrm{n}=5-8 \mathrm{mice}$ per group) was stained with antibodies against TROP2 (green) and KI-67 (red), the lectin GS-II (blue), and DAPI (grey). (A) Images were taken with a Zeiss LSM 780 confocal microscope using a 20× objective and analyzed with Zen and Fiji software. Representative images are shown, arrows show TROP2 $/$ KI-67 gland fragments, and the asterisk shows a TROP2 $/$ KI-6T gland fragment. Scale bar, $100 \mu \mathrm{m}$. (B) TROP2 ${ }^{+}$gland fragments were enumerated as a percentage of total gland fragments detected. (C) TROP2 ${ }^{+}$glands or gland fragments were assessed for KI-67 staining and the percentage of dual-positive gland fragments is shown. Statistically significant comparisons are indicated by: ${ }^{*} P<0.05,{ }^{* \star} P<0.01$, Kruskal-Wallis test with Dunn's correction. (D) The expression of gastric cancer-associated genes discovered through literature searching is shown. RNA was extracted from stomach sections from Hp+/-, KRAS+/- mice at 12 wk and gene expression was detected with the NanoString nCounter Mouse Immunology Panel. The dendrogram was produced by hierarchical clustering of gene expression and colored bars denote different treatment groups. Data come from $N=1$ NanoString experiment with $n=6-7$ mice per group from $N=2$ independent mouse experiments. \# denotes genes expressed in Mist-Kras organoids (Min et al, 2019). 

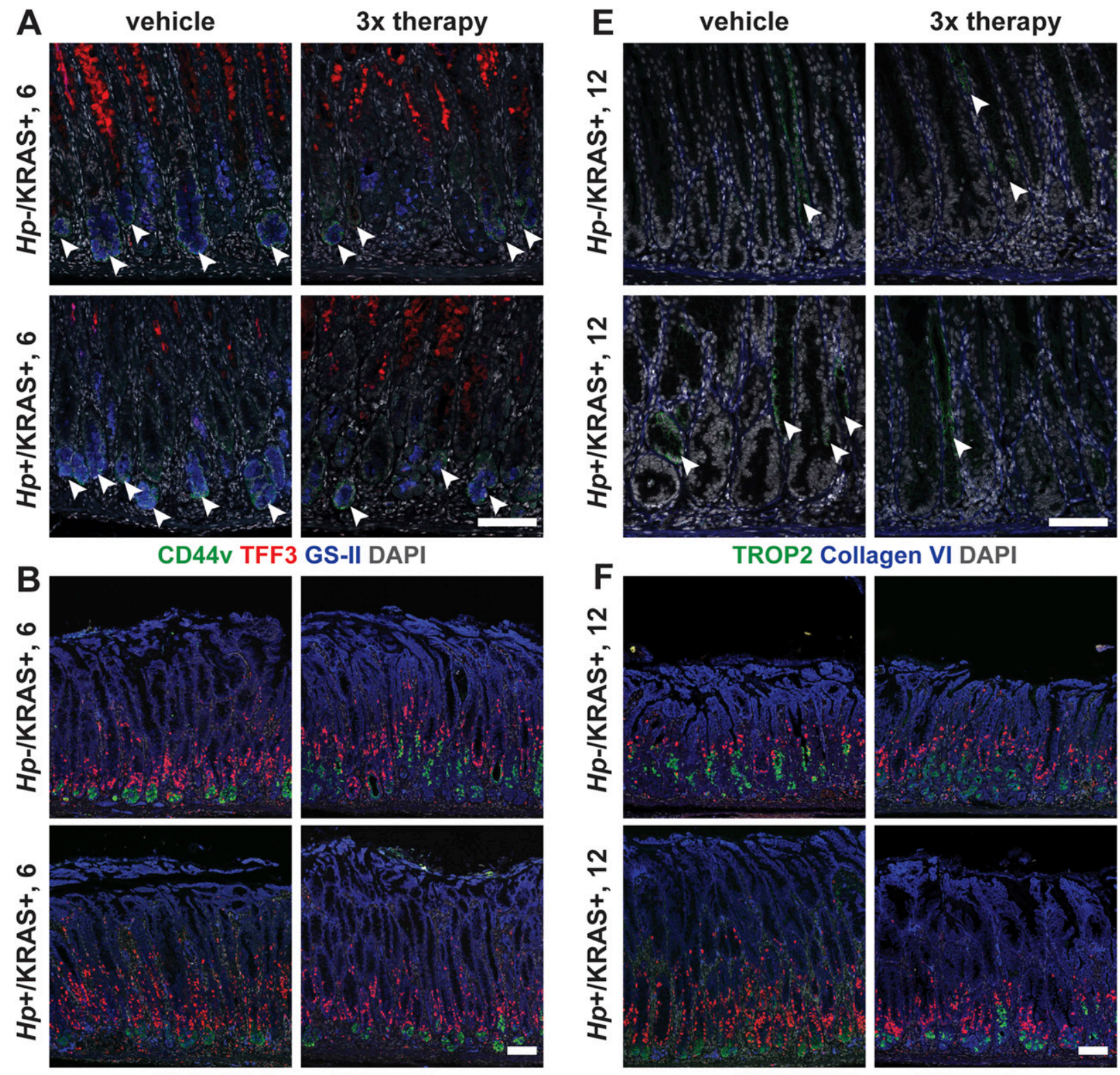

\section{KI-67 GS-II pan-CK DAPI}

C Corpus CD44v expression

D Corpus TFF3 expression
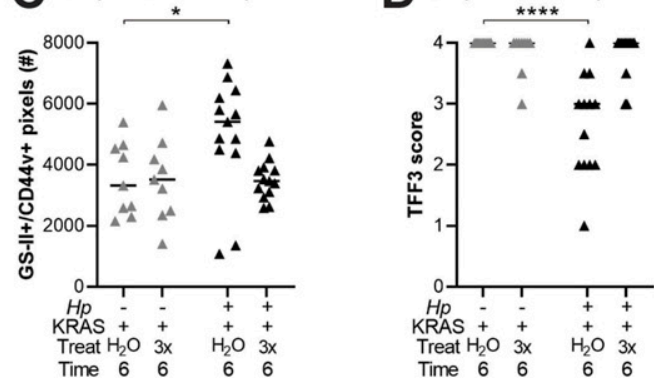

G Corpus TROP2 expression

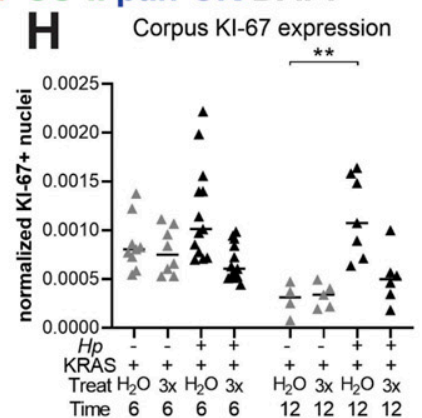

Figure 8. Antibiotic eradication prevents $\mathrm{Hp}$-associated changes in $\mathrm{Hp}+/ \mathrm{KRAS}+$ mice.

First, mice were infected with $\mathrm{Hp}$ or mock-infected, then active KRAS was induced. (A, B, C, D, E, F, G) Starting at 2 wk (A, B, C, D) or 6 wk (E, F, G), mice received 2 wk of daily antibiotic therapy (triple therapy of tetracycline, metronidazole, and bismuth, " $3 x^{\prime \prime}$ ) or vehicle control (" $\mathrm{H}_{2} \mathrm{O}$ ") Mice were euthanized after 6 ( $\left.A, B, C, D\right)$ or 12 (E, F, G) wk and immunofluorescence microscopy was used to assess tissue phenotypes. (A) Stomachs were stained with antibodies against CD44V (green, arrowheads) and TFF3 (red), the lectin GS-II (blue), and DAPI (grey) in N = 1 staining experiment. (E) Stomachs were stained with antibodies against TROP2 (green, arrowheads) and collagen VI (blue) and DAPI (grey) in N = 1 staining experiment. (B, F) Stomachs were stained with antibodies against KI-67 (red) and pan-cytokeratin (blue), the lectin GS-II (green) and DAPI 
hypothesis that concomitant $\mathrm{Hp}$ infection and active KRAS expression results in a unique gastric environment that is distinct from either $\mathrm{Hp}$-/KRAS+ or $\mathrm{Hp}+$ /KRAS- mice.

\section{Sustained $\mathrm{Hp}$ infection is necessary to elicit changes to metaplasia, dysplasia and cell proliferation}

Finally, we tested the impact of antibiotic eradication of $\mathrm{Hp}$ in two lines of experiments (Figs 8 and S13). First mice were infected with Hp or mock-infected, and active KRAS was induced. Starting at 2 wk after active KRAS induction, mice received 2 wk of "triple therapy" of tetracycline, metronidazole and bismuth (Arnold et al, 2011) or vehicle (water) as a control, and were euthanized at 6 wk (Fig $8 \mathrm{~A}$ and B). Notably, $\mathrm{Hp}+$ /KRAS + mice that received triple therapy had low CD44V (Fig 8A and C) and high TFF3 (Fig 8A and D) expression, similar to $\mathrm{Hp}$ - / KRAS + mice (whether untreated as in Fig 6E and F, or treated with triple therapy or water). Thus, eradication of $\mathrm{Hp}$ early in the course of infection prevents the altered course of metaplasia seen at 6 wk. Similarly, we tested the effects of triple therapy after 6 wk (a time point where significant $\mathrm{Hp}$-dependent changes to the tissue are already evident) with euthanasia at $12 \mathrm{wk}$ (Fig $8 \mathrm{E}$ and F). $\mathrm{Hp}+1$ KRAS + mice that received triple therapy had reduced TROP2+ glands at $12 \mathrm{wk}$ (Fig $8 \mathrm{E}$ and $\mathrm{G}$ ), suggesting that sustained $\mathrm{Hp}$ presence is necessary to accelerate dysplasia in this model. Finally, we found that at both time points antibiotic-treated $\mathrm{Hp}+/ \mathrm{KRAS}+$ mice had reduced $\mathrm{KI}-67$ staining (Fig $8 \mathrm{~B}, \mathrm{~F}$, and $\mathrm{H}$ ), demonstrating that sustained $\mathrm{Hp}$ presence is also required for the hyperproliferation phenotype in $\mathrm{Hp}+$ / KRAS+ mice.

\section{Discussion}

In this study we examined the effect of $\mathrm{Hp}$ infection in stomachs expressing active KRAS (Table 1). Up to $40 \%$ of human gastric cancers have genetic signatures of RAS activity (Deng et al, 2012; Cancer Genome Atlas Research Network, 2014). Activation of RAS and/or other oncogenic pathways in humans could be a consequence of $\mathrm{Hp}$-driven inflammation. In our model, KRAS activation serves as a tool to model the consequences of oncogenic inflammation caused by Hp infection. Because active KRAS alone is sufficient to cause gastric preneoplastic progression (Choi et al, 2016), it might be expected that Hp infection would have no impact on KRAS-driven phenotypes. However, we found that Hp infection did influence preneoplastic progression in this model. Hp infection in KRAS-expressing mice led to more severe inflammation, an altered trajectory of metaplasia, substantial cell proliferation, and increased dysplasia compared with active KRAS alone. In addition, eradication of $\mathrm{Hp}$ with antibiotics prevented these tissue changes, in accordance with a major long-term study of $\mathrm{Hp}$ eradication in
Colombian adults with precancerous lesions, which showed that continuous $\mathrm{Hp}$ presence was significantly associated with disease progression (Mera et al, 2018). Thus, our study supports the hypothesis that sustained $\mathrm{Hp}$ infection can impact the molecular course of cancer development, beyond just initiating chronic inflammation.

Different mouse models exhibit different clinical features of preneoplastic progression. For example, Helicobacter infection alone causes SPEM but does not cause foveolar hyperplasia or IM in C57BL/ 6 mice, whereas uninfected Mist1-Kras mice exhibit all of these tissue states after active KRAS induction (Petersen et al, 2017). Here, we found that the combination of sustained $\mathrm{Hp}$ infection and active KRAS expression has a unique impact on the development of gastric metaplasia that is not observed with either individual parameter. Compared with $\mathrm{Hp}-/ \mathrm{KRAS}+$ mice, $\mathrm{Hp}+$ I KRAS+ mice had no difference in foveolar hyperplasia or expression of the IM marker MUC2, but had decreased expression of the IM marker TFF3 and increased expression of the SPEM marker CD44V. Further work is needed to determine whether these changes in metaplasia marker expression may reflect increased SPEM versus a process similar to incomplete IM. To our knowledge, of the various mouse models of gastric corpus preneoplastic progression, only Mist1-Kras mice exhibit true IM (indicated by $\mathrm{TFF3}^{+}$and $\mathrm{MUC2}^{+}$glands) in $100 \%$ of mice; most other models exhibit SPEM with or without intestinalizing characteristics (Petersen et al, 2017). The finding that $\mathrm{Hp}$ infection altered TFF3 expression in Mist1-Kras mice is therefore quite striking. TFF3 expression was moderate in both treatment groups at $2 \mathrm{wk}$, and it is not yet known whether TFF3 expression may have peaked in $\mathrm{Hp}+$ /KRAS + mice at an intermediate time point, such as $4 \mathrm{wk}$, or was never as strongly expressed as in $\mathrm{Hp}$-/KRAS+ mice. Notably, several human studies have reported that the association of SPEM with gastric adenocarcinoma is equal to or even greater than that of IM (Schmidt et al, 1999; Yamaguchi et al, 2002; Halldorsdottir et al, 2003), leading to questions in the field regarding the trajectory of metaplasia development before gastric cancer onset. Our findings suggest that the trajectory of metaplasia could differ depending on whether or not $\mathrm{Hp}$ remains present in the stomach throughout preneoplastic progression.

Sustained $\mathrm{HP}$ infection also caused a striking increase in cell proliferation as indicated by KI-67 staining, and increased TROP2 staining at $12 \mathrm{wk}$. TROP2 expression was lower in our mice than what was previously reported (Riera et al, 2020), which may reflect differences in animal housing conditions, different methods of tissue fixation and processing, or components of the microbiome (although antibiotic perturbation in $\mathrm{Hp}$ - / KRAS + mice had no effect on expression of TROP2 or metaplasia markers). Nonetheless, within our controlled experiments, TROP2 staining was greatest in $\mathrm{Hp}+$ I KRAS+ mice, suggesting that infection accelerates the onset of

(grey) in $\mathbf{N}=2$ staining experiments. (C, D, G, H) Three to five representative images per mouse were quantitatively or semi-quantitatively assessed and the median value for each mouse is plotted. Bars on the graphs indicate the median value for each mouse group. (C) The number of GS-II $/$ CD44V ${ }^{+}$pixels per image was quantified. (D) TFF3 staining was semi-quantitatively scored in a blinded fashion. Nonspecific staining was not included in the score (see Fig S9). (G) The percentage of TROP2 ${ }^{+}$gland

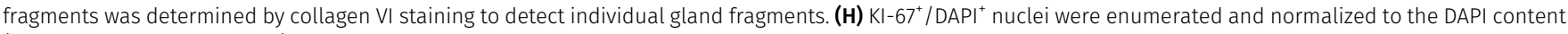
(total number of $\mathrm{DAPI}^{+}$pixels) of each image. Statistically significant comparisons are indicated by: ${ }^{*} P<0.05,{ }^{* *} P<0.01,{ }^{* * * *} P<0.0001$, Kruskal-Wallis test with Dunn's correction. Representative images are shown. Scale bars, $100 \mu \mathrm{m}$. 
Table 1. Summary of differences between $H p-/ K R A S+$ and $H p+/ K R A S+$ mice.

\begin{tabular}{|c|c|c|c|}
\hline Parameter & $\mathrm{Hp}-/$ KRAS+ & Hp+/KRAS+ & Relevance to humans \\
\hline Immune gene expression & $\begin{array}{l}\text { Less up-regulation of T cell and } \\
\text { macrophage-related genes }\end{array}$ & $\begin{array}{l}\text { Up-regulation of genes related to T cells } \\
\text { and T-cell exhaustion, macrophages } \\
\text { and gastric cancer; unique } \\
\text { inflammatory gene signature }\end{array}$ & $\begin{array}{l}\text { Many genes up-regulated in } \mathrm{Hp}+\text { /KRAS+ } \\
\text { mice were shown to be up-regulated in } \\
\text { human gastrointestinal cancers (Alpizar- } \\
\text { Alpizar et al, 2012; Lee et al, 2012; Jin et } \\
\text { al, 2015; Huang et al, 2018; Molina-Castro } \\
\text { et al, 2020) }\end{array}$ \\
\hline T cells & $\begin{array}{l}\text { Moderate T cells, predominantly } \mathrm{CD} 4^{+} . \mathrm{T} \\
\text { cells mostly restricted to the base of the } \\
\text { glands }\end{array}$ & $\begin{array}{l}\text { Many T cells, predominantly } \mathrm{CD}^{+} \text {, } \\
\text { including FOXP3 }{ }^{+} \text {. T cells extend } \\
\text { throughout the glands }\end{array}$ & $\begin{array}{l}\text { Hp infection leads to recruitment and } \\
\text { activation of T cells (Akhiani et al, 2002; } \\
\text { Sayi et al, 2009; Velin et al, 2009), which } \\
\text { may lead to mucosal damage and } \\
\text { accumulation of mutations (Shi et al., } \\
\text { 2010)(Stoicov et al, 2009). Exhausted T } \\
\text { cells may be targeted by immune } \\
\text { checkpoint inhibitors (Figueroa-Protti } \\
\text { et al, 2019) }\end{array}$ \\
\hline Macrophages & $\begin{array}{l}\mathrm{F} 4 / 80^{+} / \mathrm{CD} 163^{+}(\mathrm{M} 2) \text { cells are present, } \\
\text { with a few } \mathrm{F} 4 / 80^{+} / \mathrm{MHC} \text { class } \mathrm{I}^{+}(\mathrm{M} 1) \text { as } \\
\text { well }\end{array}$ & $\begin{array}{l}\text { Some } \mathrm{F} 4 / 80^{+} / \mathrm{MHC} \text { class } \mathrm{II}^{+}(\mathrm{M} 1) \text { cells are } \\
\text { present, with very few } \mathrm{F} 4 / 80^{+} / \mathrm{CD} 63^{+} \\
\text {(M2) }\end{array}$ & $\begin{array}{l}\text { M2 macrophages are found in human } \\
\text { SPEM and IM (Petersen et al, 2014). } \\
\text { Macrophages can infiltrate into gastric } \\
\text { tumors and are associated with worse } \\
\text { surgical outcomes (Ishigami et al, 2003) }\end{array}$ \\
\hline $\begin{array}{l}\text { Metaplasia marker } \\
\text { expression ( } 6 \mathrm{wk})\end{array}$ & Moderate CD44v9, high TFF3, low MUC2 & High CD44V9, moderate TFF3, low MUC2 & \multirow{2}{*}{$\begin{array}{l}\text { SPEM (CD44V10+) and IM (MUC2+, TFF3+) } \\
\text { are both precursor lesions associated } \\
\text { with human gastric adenocarcinoma } \\
\text { (Schmidt et al, 1999; Yamaguchi et al, } \\
\text { 2002; Halldorsdottir et al, 2003) }\end{array}$} \\
\hline $\begin{array}{l}\text { Metaplasia marker } \\
\text { expression ( } 12 \mathrm{wk} \text { ) }\end{array}$ & Moderate CD44v9, high TFF3, low MUC2 & High CD44v9, low TFF3, low MUC2 & \\
\hline Cell proliferation & $\begin{array}{l}\text { Moderate numbers of } \mathrm{KI}-67^{+} \text {cells near } \\
\text { the base of the glands }\end{array}$ & $\begin{array}{l}\text { Far more of } \mathrm{KI}-67^{+} \text {cells, near the base } \\
\text { and throughout the glands }\end{array}$ & $\begin{array}{l}\text { Cell proliferation was greater in IM than } \\
\text { in gastritis or healthy human stomachs } \\
\text { (Erkan et al, 2012) }\end{array}$ \\
\hline
\end{tabular}

HAI, histological activity index.

dysplasia. Although almost all of the TROP2 ${ }^{+}$glands in $\mathrm{Hp}^{+} / \mathrm{KRAS}+$ mice had co-localized $\mathrm{KI}-67$ staining, demonstrating proliferation of dysplastic glands, there were also many $\mathrm{KI}^{-67^{+}}$cells in $\mathrm{TROP2}^{-}$ glands. Future studies will seek to elucidate the specific cell types that are proliferating in $\mathrm{Hp}+/ \mathrm{KRAS}+$ mice. Despite the enhanced proliferation of dysplastic glands, $\mathrm{Hp}+/ \mathrm{KRAS}+$ mice did not develop gastric tumors within $12 \mathrm{wk}$. One limitation of our study is that the Mist1 promoter is expressed outside the stomach in secretory lineages, including the salivary glands. Approximately $\sim 4$ mo after active KRAS induction, Mist1-Kras mice require humane euthanasia because of salivary gland tumors. Thus, we cannot test whether $\mathrm{Hp}$ infection promotes even more severe phenotypes, such as tumor development, at later time points. Specifically targeting active KRAS to the chief cells via other promoters could overcome this hurdle. However, $\mathrm{Hp}+$ /KRAS + mice did have increased expression of genes known to be associated with gastrointestinal cancers. It may be that at least some of these genes are associated with gastric cancer simply because they reflect $\mathrm{Hp}$ infection, the biggest risk factor for gastric cancer development.

Our study does not define whether the combination of sustained $\mathrm{Hp}$ infection and active KRAS expression is additive (activation of parallel pathways) or synergistic (activation of overlapping pathways). The presence of a unique inflammatory gene signature and altered metaplasia marker expression in $\mathrm{Hp}+$ /KRAS+ mice could indicate that each perturbation activates distinct pathways. In addition, phosphoERK1/2 staining was similar between $\mathrm{Hp}+/$ KRAS + and $\mathrm{Hp}$-/ KRAS + mice, 
indicating that $\mathrm{Hp}$ infection does not further activate the MAP kinase pathway in KRAS + mice. However, more studies are needed to address the overlap in the pathways downstream of $\mathrm{Hp}$ infection and active KRAS expression in this model. Interestingly, we found that a few $\mathrm{Hp}+$ I KRAS + mice naturally cleared their infection, yet still had a high degree of immunopathology. A limitation of modeling $\mathrm{Hp}$ infection in mice is the inability to monitor bacterial burdens over time. It may be that the mice in question cleared their infection just before euthanasia, with no time for $\mathrm{Hp}$-driven tissue changes to reverse. Alternatively, $\mathrm{Hp}$ infection may lead to a "point of no return," after which immunopathology develops even in the absence of $\mathrm{Hp}$. This hypothesis has been used to explain the lack of detectable $\mathrm{Hp}$ in about half of human gastric tumors (Atherton \& Blaser, 2009; Peleteiro et al, 2012). However, we found that antibiotic eradication of $\mathrm{Hp}$ after $6 \mathrm{wk}$ prevented the accelerated dysplasia and hyperproliferation phenotypes at $12 \mathrm{wk}$. Thus, if a "point of no return" exists in this model, it must occur after 6 wk.

We note that no significant differences in metaplasia or dysplasia marker expression were observed between $\mathrm{Hp}$-/KRAS+ mice and $\mathrm{Hp}+/$ KRAS + mice at $2 \mathrm{wk}$, suggesting that the adaptive immune response to $\mathrm{Hp}$ infection may be what promotes the differences in metaplasia and dysplasia observed at later time points. This observation agrees with previous findings that T cells were necessary for Helicobacter-associated gastritis (Ernst et al, 1997; Eaton et al, 2001) and metaplasia development (Roth et al, 1999). The immune response seen in $\mathrm{Hp}+/$ KRAS + mice at 6 and especially 12 wk far exceeded what was observed in either $\mathrm{Hp}+$ /KRAS- or $\mathrm{Hp}$-/KRAS+ mice, and indeed is much greater than what is typically seen in $\mathrm{Hp}$ mouse models. Notably, this inflammation did not eradicate $\mathrm{Hp}$ : most $\mathrm{Hp}+/$ KRAS + mice remained colonized at $12 \mathrm{wk}$. Hp cells were observed within the lumen of metaplastic glands, where they may be protected from direct immune cell interaction. In addition, $\mathrm{Hp}$ has multiple strategies to prevent immune-mediated clearance (Salama et al, 2013), including disruption of normal T cell functions by: triggering up-regulation of PD-L1, a T-cell inhibitory ligand that binds programmed cell death protein-1 (PD-1), on gastric epithelial cells, leading to T-cell exhaustion (Das et al, 2006); inducing anergy through promoting T-cell expression of the CTLA-4 co-receptor (Anderson et al, 2006); inhibiting T-cell proliferation and normal effector functions with the vacuolating cytotoxin VacA (Gebert et al, 2003); and the induction of tolerogenic dendritic cells, which promote the differentiation of naive $T$ cells into immunosuppressive regulatory T cells (Salama et al, 2013). It remains unknown whether and to what extent $\mathrm{Hp}$ may disrupt T-cell functions in our model. Hp+/KRAS+ mice were unique in their up-regulation of Foxp 3 and had FOXP3 ${ }^{+} \mathrm{T}$ cells at 12 wk, but these cells were not sufficient to limit immunopathology. As well, in $\mathrm{Hp}+/ \mathrm{KRAS}+$ mice we observed strong transcriptional upregulation of T-cell exhaustion-related genes, such as Pdcd1 (PD-1), and Ctla4, implicated in T-cell anergy. By immunohistochemistry, we saw evidence of PD-1 expression in both $\mathrm{Hp}-/$ KRAS+ and $\mathrm{Hp}+/$ KRAS+ mice. Further studies are needed to characterize the exact nature of immune cell polarization differences between treatment groups; to confirm whether the $\mathrm{T}$ cells observed in $\mathrm{Hp}+/$ KRAS + mice may be exhausted, anergic, or senescent; and to test whether immunosuppression or immunomodulation would be protective against Hp's effects in the model. Nonetheless, it is clear that the combination of $\mathrm{Hp}$ infection and active KRAS expression leads to a potent and unique inflammatory state. Given that immunotherapy is still underused in gastric cancer (Zayac \& Almhanna, 2020) and only a subset of patients benefit from such treatments (Figueroa-Protti et al, 2019), a better understanding of how active $\mathrm{Hp}$ infection may alter the immune microenvironment during gastric metaplasia and cancer development is urgently needed and may lead to new therapeutic strategies.

When Hp was first discovered to be a bacterial carcinogen, studies using tissue histology rarely detected $\mathrm{Hp}$ within gastric tumors. Such studies may have helped establish the belief that although $\mathrm{Hp}$ initiates the gastric cancer cascade, by the time gastric cancer is developed, $\mathrm{HP}$ no longer matters-the so-called "hit-and-run" model. However, more sensitive methods detect $\mathrm{Hp}$ in about half of gastric tumors (Tang et al, 2005; Cristescu et al, 2015; Talarico et al, 2018), indicating that a large percentage of patients maintain active $\mathrm{Hp}$ infection throughout cancer development. Notably, Hp eradication combined with endoscopic resection of early gastric cancer significantly reduces metachronous gastric cancer (Choi et al, 2018). As well, a recent study of $135 \mathrm{Hp}$ seropositive subjects with IM found that patients with active $\mathrm{Hp}$ infection (determined by histology and/or sequencing) were significantly more likely to have somatic copy number alterations, and that patients with somatic copy number alterations were more likely to experience IM progression (Huang et al, 2018). Given these observations, there is an urgent need for preclinical models that identify unique features of gastric neoplasia with versus without concomitant $\mathrm{Hp}$ infection, both to understand the etiology of gastric cancer and to determine the impact of infection on different therapeutic approaches. We have shown here that $\mathrm{Hp}$ can significantly impact metaplasia and dysplasia development, which suggests that gastric preneoplastic progression can develop differently in the presence versus absence of $H p$. Future studies will elucidate the molecular mechanism(s) through which $\mathrm{Hp}$ exerts its effects in this model, and test whether active $\mathrm{Hp}$ infection during metaplasia or cancer may represent a therapeutic vulnerability that could be targeted with immunotherapy.

\section{Materials and Methods}

\section{Ethics statement}

All authors had access to the study data and reviewed and approved the final manuscript. All mouse experiments were performed in accordance with the recommendations in the National Institutes of Health Guide for the Care and Use of Laboratory Animals. The Fred Hutchinson Cancer Research Center is fully accredited by the Association for Assessment and Accreditation of Laboratory Animal Care and complies with the United States Department of Agriculture, Public Health Service, Washington State, and local area animal welfare regulations. Experiments were approved by the Fred Hutch Institutional Animal Care and Use Committee, protocol number 1531.

\section{H. pylori strains and growth conditions}

H. pylori strain PMSS1, which is also called 10700 and which is CagA ${ }^{+}$ with an active type IV secretion system (Lee et al, 1997; Arnold et al, 2011), and derivatives were cultured at $37^{\circ} \mathrm{C}$ with $10 \% \mathrm{CO}_{2}$ and $10 \%$ $\mathrm{O}_{2}$ in a trigas incubator (MCO-19M; Sanyo). Cells were grown on solid 
media containing $4 \%$ Columbia agar (BD Biosciences), 5\% defibrinated horse blood (HemoStat Laboratories) $0.2 \% \beta$-cyclodextrin (Acros Organics), $10 \mu \mathrm{g} / \mathrm{ml}$ vancomycin (Sigma-Aldrich), $5 \mu \mathrm{g} / \mathrm{ml}$ cefsulodin (Sigma-Aldrich), $2.5 \mathrm{U} / \mathrm{ml}$ polymyxin B (Sigma-Aldrich), $5 \mu \mathrm{g} / \mathrm{ml}$ trimethoprim (Sigma-Aldrich), and $8 \mu \mathrm{g} / \mathrm{ml}$ amphotericin $\mathrm{B}$ (Sigma-Aldrich). For mouse infections, bacteria grown on horse blood plates were used to inoculate liquid media (BB10) containing 90\% (vol/vol) Brucella broth (BD Biosciences) and 10\% fetal bovine serum (Gibco), which was cultured shaking at 200 rpm overnight in a MaxQ 2000 orbital shaker (Thermo Fisher Scientific) and grown to an optical density at $600 \mathrm{~nm}$ of $0.4-0.6$ (mid-log phase), from which an inoculum of $\sim 5 \times 10^{7} \mathrm{Hp}$ cells per $100 \mu \mathrm{l}$ BB10 was prepared. To determine $\mathrm{Hp}$ titers in the stomach, harvested tissues were weighed, homogenized, serially diluted, and plated on the solid media described above, with the addition of bacitracin $(200 \mu \mathrm{g} / \mathrm{ml}$; Acros Organics) to prevent growth of the stomach microbiota.

\section{Mist1-Kras mouse model}

A breeding pair of Mist1-CreERT2 Tg/+; LSL-K-Ras (G12D) Tg/+ ("Mist1-Kras") mice on the C57BL/ 6 background, described previously (Choi et al, 2016), was obtained from Vanderbilt University (E Choi and JR Goldenring) and used to establish a colony at Fred Hutchinson Cancer Research Center. Mice were housed two to five per cage, with cages docked in HEPA-filtered ventilation racks that provide airflow control on a $12 \mathrm{~h}$ light/dark cycle, and had access to chow (LabDiet) and water ad libitum. At weaning, ear punches were collected and used for genotyping as previously described (Choi et al, 2016) with the following primers: Mist1 WT F: CCAAGATCGAGACCCTCACG; Mist1 WT R: ACACACACAGCCCTTAGCTC Mist1 Cre F: ACCGTCAGTACGTGAGATATCTT; Mist1 Cre R: CCTGAAGATGT TCGCGATTATCT; active KRAS F: TCTCTGCAGTTGTTGGCTCCAAC; active KRAS R: GCCTGAAGAACGAGATCAGCAGCC. Healthy 8- to 16-wk-old male and female mice (randomly allocated to treatment groups) were infected with $5 \times 10^{7}$ mid-log culture Hp cells in $100 \mu \mathrm{l}$ of BB10, or mock-infected with $100 \mu \mathrm{l}$ of BB10, via oral gavage. To induce active (oncogenic) KRAS expression, mice received three subcutaneous doses of $5 \mathrm{mg}$ of tamoxifen (Sigma-Aldrich) in corn oil (SigmaAldrich) over $3 \mathrm{~d}$, or were sham-induced with corn oil, starting $1 \mathrm{~d}$ after $\mathrm{Hp}$ or mock infection. For antibiotic eradication, mice received "triple therapy" of $4.5 \mathrm{mg} / \mathrm{ml}$ metronidazole, $10 \mathrm{mg} / \mathrm{ml}$ tetracycline hydrochloride and $1.2 \mathrm{mg} / \mathrm{ml}$ bismuth subcitrate, or vehicle (water), by oral gavage (Arnold et al, 2011). Mice received six doses in $7 \mathrm{~d}$, 2 wk in a row. Mice were humanely euthanized by $\mathrm{CO}_{2}$ inhalation followed by cervical dislocation 2, 6, or 12 wk after infection and transgene induction. Stomachs were aseptically harvested and most of the forestomach (non-glandular region) was discarded, leaving only the squamocolumnar junction between the forestomach and glandular epithelium. Approximately one-third of the stomach was homogenized and plated to enumerate Hp. The remaining approximately two-thirds of the stomach was fixed in $10 \%$ neutral-buffered formalin phosphate (Thermo Fisher Scientific), then embedded in paraffin and cut into $4-\mu \mathrm{m}$ sections on positively charged slides. $\mathrm{Hp}+/$ KRAS + and $\mathrm{Hp}$-/KRAS mice did not exhibit overall health differences; body weights and behaviors were similar at time of euthanasia.

\section{Histology}

Stomach sections were stained with hematoxylin and eosin ( $H \& E$ ). A veterinary pathologist (AL Koehne) scored the slides in a blinded fashion according to criteria adapted from Rogers (2012). Corpus tissue was evaluated for inflammation, epithelial defects, oxyntic atrophy, hyperplasia (tissue thickness), hyalinosis, pseudopyloric metaplasia, mucous metaplasia, and dysplasia. The sums of the individual scores for each criterion were summed to generate an HAl score. Scoring criteria are described below. HAI was not correlated with sex or with age of mice at euthanasia.

\section{Inflammation}

Multifocal aggregates of inflammatory cells merit a score of 1. As the aggregates coalesce across multiple high-power fields (40× objective), the score increases to 2 . Sheets of inflammatory cells and/ or lymphoid follicles in the mucosa or submucosa receive a score of 3. Florid inflammation that extends into or through the muscularis and/or adventitia is a score of 4 .

\section{Epithelial defects}

A tattered epithelium with occasional dilated glands is a score of 1. As the epithelium becomes attenuated and ectatic glands become more numerous, the score increases to 2. Inapparent epithelial lining of the surface with few recognizable gastric pits are given a score of 3 . Score 4 is reserved for mucosal erosions.

\section{Oxyntic atrophy}

The oxyntic mucosa is defined by the presence of chief and parietal cells. Loss of up to half of the chief cells merit a score of 1 . In instances with near complete loss of chief cells and minimal loss of parietal cells, a score 2 is assigned. The absence of chief cells with half the expected number of parietal cells is given a score of 3 . Score 4 signifies near total loss of both chief and parietal cells.

\section{Surface epithelial hyperplasia}

This score indicates elongation of the gastric gland due to increased numbers of surface (foveolar) and/or antral-type epithelial cells. Relative to the expected length of a normal gastric pit, a score of 1 indicates a $50 \%$ increase in length. A score of 2 is twice the expected length, a score of 3 is three times the expected length, and a score of 4 is four times the expected length.

\section{Hyalinosis}

This mouse-specific gastritis lesion refers to the presence of brightly eosinophilic round or crystalline structures in the murine gastric surface epithelium. The presence of epithelial hyalinosis is given a score of 1 , whereas absence of hyalinosis is a score 0.

\section{Pseudopyloric metaplasia}

Pseudopyloric metaplasia is the loss of oxyntic mucosa and replacement with glands of a more antral phenotype. The score indicates the amount of replacement by antralized glands. Less than $25 \%$ replacement is a score of 1, 26-50\% replacement is a score of $2,51-75 \%$ replacement is a score of 3 , and greater than $75 \%$ replacement is a score of 4 . 


\section{Mucous metaplasia}

This mouse-specific gastritis lesion is defined as the replacement of oxyntic cells with mucous producing cells that resemble Brunner's glands of the duodenum. The score is assigned based on the percentage of mucosa affected. A score 1 indicates less than $25 \%$ involvement, a score of 2 indicates $26-50 \%$ involvement, a score of 3 is $51-75 \%$ involvement, and a score of 4 means that greater than $75 \%$ of the mucosa is involved.

\section{Dysplasia}

Dysplasia indicates a cellular abnormality of differentiation. In score 1 lesions, the glands are elongated with altered shapes, backto-back forms, and asymmetrical cellular piling. In score 2, the dysplastic glands may coalesce with glandular ectasia, branching, infolding, and piling of cells. Gastric intraepithelial neoplasia is given a score of 3 and invasive carcinoma is a score of 4 . The dysplasia score describes the most severe lesion(s) in each mouse.

\section{Gene expression analysis}

RNA was extracted from five 4- $\mu$ m FFPE stomach sections per mouse using the AllPrep DNA/RNA FFPE Kit (QIAGEN). To specifically investigate the impact of $\mathrm{Hp}$ on the host immune response, inflammatory gene expression was detected using the nCounter Mouse Immunology Panel (NanoString), which detects more than 550 mouse immune-related genes. Gene expression differences were detected using nSolver software (NanoString) and are given in Table S1. Volcano plots were constructed by taking the $\log _{2}$ of the fold change and the $-\log _{10}$ of the unadjusted $P$-value for each gene. The $P_{\text {adjusted }}$ lines show genes meeting the threshold for significance after correction with the BenjaminiYekutieli procedure for controlling the false discovery rate. Hierarchical clustering was performed and heat maps were generated through HeatMapper (Babicki et al, 2016) using the average linkage method with Euclidian distance, with $\log _{2}$-transformed gene expression data. Clustering was applied to rows (genes) and columns (mice). To identify the unique gene signature in $\mathrm{Hp}+/$ KRAS + mice, gene expression values were normalized to the geometric mean of the expression in $\mathrm{Hp}$-/KRAS- mice, and all genes were identified for which the geometric mean of the fold change in $\mathrm{Hp}+/$ KRAS + mice was $>2$ and in $\mathrm{Hp}+/$ KRAS- and $\mathrm{Hp}-/$ KRAS+ mice was $<1.5$, or the geometric mean of the fold change in $\mathrm{Hp}+/$ KRAS+ mice was $<0.5$ and in $\mathrm{Hp}+$ /KRAS- and $\mathrm{Hp}$-/KRAS+ mice was $>0.667$.

\section{Multiplex immunohistochemistry for immune cell detection}

Slides were baked for $60 \mathrm{~min}$ at $60^{\circ} \mathrm{C}$ and then dewaxed and stained on a Leica BOND RX system (Leica) using Leica BOND reagents for dewaxing (Dewax Solution), antigen retrieval/antibody stripping (Epitope Retrieval Solution 2), and rinsing (Bond Wash Solution). Antigen retrieval and antibody stripping steps were performed at $100^{\circ} \mathrm{C}$ with all other steps at ambient temperature. Endogenous peroxidase was blocked with $3 \% \mathrm{H}_{2} \mathrm{O}_{2}$ for 5 min followed by protein blocking with 10\% normal mouse immune serum diluted in TCT buffer (0.05M Tris, $0.15 \mathrm{M} \mathrm{NaCl}, 0.25 \%$ casein, $0.1 \%$ Tween-20, 0.05\% ProClin300, pH 7.6) for 10 min. Primary and secondary antibodies are given in Table S2. The first primary antibody (position 1) was applied for $60 \mathrm{~min}$ followed by the secondary antibody application for $10 \mathrm{~min}$ and application of the reactive Opal fluorophore (Akoya) for 10 min. A high-stringency wash was performed after the secondary and tertiary applications using high-salt TBST solution (0.05M Tris, $0.3 \mathrm{M} \mathrm{NaCl}$, and 0.1\% Tween-20, pH 7.2-7.6). Undiluted, species-specific Polymer HRP was used for all secondary applications, either Leica's PowerVision PolyHRP anti-Rabbit Detection or ImmPress Goat anti-Rat IgG Polymer Detection Kit (Vector Labs) as indicated in Table S2. The primary and secondary antibodies were stripped with retrieval solution for $20 \mathrm{~min}$ before repeating the process with the second primary antibody (position 2) starting with a new application of $3 \% \mathrm{H}_{2} \mathrm{O}_{2}$. The process was repeated until seven positions were completed. For the eighth position, following the secondary antibody application, Opal TSA-DIG was applied for 10 min, followed by the 20 min stripping step in retrieval solution and application of Opal 780 Fluor for 10 min with high stringency washes performed after the secondary, TSA-DIG, and Opal 780 Fluor applications. Slides were removed from the stainer and stained with DAPI for 5 min, rinsed for 5 min, and coverslipped with Prolong Gold Antifade reagent (Invitrogen/ Life Technologies). Slides were cured overnight at room temperature, and then whole slide images were acquired on the Vectra Polaris Quantitative Pathology Imaging System (Akoya Biosciences). The entire tissue was selected for imaging using Phenochart and multispectral image tiles were acquired using the Polaris. Images were spectrally unmixed using Phenoptics inForm software and exported as multi-image TIF files, which were analyzed with HALO image analysis software (Indica Labs). DAPI was used to detect individual cells and then cells expressing each marker were automatically detected based on signal intensity, and reported as a percentage of DAPI-positive cells.

\section{Immunofluorescence microscopy of epithelial phenotypes}

Stomach sections were prepared as described above. To validate the antibodies used to detect IM, the entire intestinal tract from duodenum to colon was removed from an untreated C57BL/ 6 mouse. The cecum was discarded and the unflushed intestinal tract was rolled as a "Swiss roll," fixed in 10\% neutral-buffered formalin, paraffin-embedded, and sectioned. Tissue sections were deparaffinized with Histo-Clear solution (National Diagnostics) and rehydrated in decreasing concentrations of ethanol. Antigen retrieval was performed by boiling slides in $10 \mathrm{mM}$ sodium citrate (Thermo Fisher Scientific) or Target Retrieval Solution (Agilent Dako) in a pressure cooker for $15 \mathrm{~min}$. Slides were incubated with Protein Block, Serum Free (Agilent Dako) for 90 min at room temperature. Primary antibodies (Table S3) were diluted in Protein Block, Serum Free, or Antibody Diluent, Background Reducing (Agilent Dako), and applied to the slides overnight at $4^{\circ} \mathrm{C}$. Secondary antibodies were diluted 1:500 in Protein Block, Serum Free and slides were incubated for $1 \mathrm{~h}$ at room temperature protected from light. Slides were mounted in ProLong Gold Antifade reagent with DAPI (Invitrogen) and allowed to cure for $24 \mathrm{~h}$ at room temperature before imaging. Slides were imaged on a Zeiss LSM 780 laser-scanning confocal microscope using Zen software (Zeiss) and three to five representative images of the corpus were taken.

\section{Quantitation of staining}

Three to five representative images of corpus tissue per mouse were used for staining analysis, and the median value was reported for each mouse. Investigators were blinded to the treatment groups. Tissues were analyzed in Zen (ZEISS) and Fiji (Schindelin et al, 2012). KI-67, GS-II, CD44V10 (orthologous to human CD44V9 and referred to herein as "CD44V"), and TROP2 markers were quantified from fluorescently immunolabelled tissue sections by custom-made scripts developed in MATLAB 2019a. 
Scripts can be found on Github at https://github.com/salama-lab/ stomach-image-quantitation.

After background subtraction and denoising in each channel, positive pixels for DAPI, GS-II, CD44V, or TROP2 were identified by image binarization using the Otsu method and morphological filtering. When appropriate, individual glands were segmented using the cytokeratin signal, which is predominant in glandular structures, or using the complement image of the collagen VI signal, which is excluded from glandular structures. For GS-II quantification, the fractional area of cytokeratin staining positive for GS-II was recorded. For TROP2 quantification, the fractional area of each gland fragment identified by collagen VI labeling was recorded, and gland fragments with $\geq 10 \%$ TROP2-positive pixels were considered TROP2-positive. To identify GS-II and CD44V double-positive regions, the GS-II binary mask was first dilated by a few pixels because GS-II is cytoplasmic and CD44V is membrane-bound. The resulting number of overlapping pixels per image was then recorded. To assess KI-67 staining, individual KI-67-positive nuclei were identified using a watershed algorithm after distance transformation of the binarized signal, and then normalized by dividing by the total number of DAPI-positive pixels in the image.

TFF3, MUC2, and dual-positive TROP2/KI-67 staining were manually assessed. To assess TFF3 staining, images were scored manually using a semi-quantitative scale with the following criteria: $0=$ no staining, $1=1-25 \%$ of glands are positive, $2=26-50 \%$ of glands are positive, $3=51-75 \%$ of glands are positive, $4 \geq 75 \%$ of glands are positive for TFF3. Positive TFF3 signal manifests as moderately bright, cell-associated staining with goblet cell-like morphology. Overly bright staining without distinct goblet-like morphology, and / or staining within the gland lumen (not cell-associated), was observed near the top of the glands in $\mathrm{Hp}$-/KRAS- (healthy control) mice and was considered false-positive staining. To assess MUC2 staining, glands were detected by cytokeratin staining, and $\mathrm{MUC2}^{+}$ and $\mathrm{MUC2}^{-}$glands were manually counted. To assess gland fragments dual-positive for TROP2 and $\mathrm{KI}-67$, regions of TROP2 ${ }^{+}$staining that contained $\mathrm{KI}-67^{+}$nuclei were counted and expressed as a percentage of all TROP2 ${ }^{+}$glands.

\section{Type IV secretion system activity}

Hp strain PMSS1 was recovered from infected mice after euthanasia by serial dilution plating, described above, and five or six individual colonies per mouse were expanded and frozen at $-80^{\circ} \mathrm{C}$. Colonies were then grown and used in co-culture experiments with AGS cells (from a human gastric adenocarcinoma cell line; ATCC CRL-1739) as previously described (Martinez et al, 2019). The input strain of PMSS1 (freezer stock) served as a positive control and a PMSS1 $\triangle$ cagE mutant (Martinez et al, 2019) served as a negative control. Infections were performed in triplicate and supernatants were collected after $24 \mathrm{~h}$ of co-culture. IL-8 was detected using a human IL-8 ELISA kit from BioLegend.

\section{Statistical analyses}

Volcano plots and heat maps were constructed from data generated by nSolver software (NanoString). For Nanostring analysis, $P_{\text {adjusted }}$ values were generated in nSolver with the Benjamini-
Yekutieli procedure for controlling the false discovery rate. Other statistics were performed in GraphPad Prism v7.01. Comparisons of three or more groups were performed with the Kruskal-Wallis test followed by Dunn's multiple test correction. $P<0.05$ was considered statistically significant. For histopathological evaluation of stomach sections and quantitation of staining, experimenters were blinded to the treatment groups.

\section{Data Availability}

Gene expression data are found in Table S1.

\section{Supplementary Information}

Supplementary Information is available at https://doi.org/10.26508/lsa. 202000967

\section{Acknowledgements}

The authors wish to acknowledge Savanh Chanthaphavong and Louis Kao for assistance with experimental histopathology and Alicia M Meyer for assistance with mouse experiments. This work was funded by an Innovation Grant from the Pathogen-Associated Malignancies Integrated Research Center at Fred Hutchinson Cancer Research Center and National Institutes of Health (NIH) R01 Al54423 (to NR Salama). Research was supported by the Cellular Imaging, Comparative Medicine, Genomics \& Bioinformatics, and Research Pathology Shared Resources of the Fred Hutch/University of Washington Cancer Consortium (P30 CA015704). VP O'Brien is a Cancer Research Institute Irvington Fellow supported by the Cancer Research Institute, and was also supported by a Debbie's Dream Foundation-American Association for Cancer Research (AACR) Gastric Cancer Research Fellowship, in memory of Sally Mandel (18-40-41-OBRI). AE Rodriguez was supported by the Jacques Chiller Award from the Department of Microbiology, University of Washington. JR Goldenring was supported by Department of Veterans Affairs Merit Review Award IBX000930, NIH R01 DK101332, Department of Defense (DOD) CA160479, and a Cancer UK Grand Challenge Award. E Choi was supported by DOD CA160399, NIH R37 CA244970, and pilot funding from Vanderbilt Digestive Disease Research Center DK058404 and a Vanderbilt-Ingram Cancer Center GI SPORE P50CA236733.

\section{Author Contributions}

VP O'Brien: conceptualization, formal analysis, funding acquisition, validation, investigation, visualization, methodology, and writing-original draft, review, and editing.

AL Koehne: investigation, methodology, and writing-review and editing.

J Dubrulle: software, formal analysis, methodology, and writingreview and editing.

AE Rodriguez: investigation and writing-review and editing.

CK Leverich: investigation and writing-review and editing.

VP Kong: investigation, methodology, and writing-review and editing. JS Campbell: investigation and writing-review and editing.

RH Pierce: conceptualization, resources, and writing-review and editing.

JR Goldenring: conceptualization, resources, and writing-review and editing. 
E Choi: conceptualization, resources, and writing-review and editing.

NR Salama: conceptualization, supervision, funding acquisition, and writing-review and editing.

\section{Conflict of Interest Statement}

The authors declare that they have no conflict of interest.

\section{References}

Akhiani AA, Pappo J, Kabok Z, Schon K, Gao W, Franzen LE, Lycke N (2002) Protection against Helicobacter pylori infection following immunization is IL-12-dependent and mediated by Th1 cells. J Immunol 169: 6977-6984. doi:10.4049/jimmunol.169.12.6977

Allen LA, Beecher BR, Lynch JT, Rohner OV, Wittine LM (2005) Helicobacter pylori disrupts NADPH oxidase targeting in human neutrophils to induce extracellular superoxide release. J Immunol 174: 3658-3667. doi:10.4049/jimmunol.174.6.3658

Alpizar-Alpizar W, Christensen IJ, Santoni-Rugiu E, Skarstein A, Ovrebo K, Illemann M, Laerum OD (2012) Urokinase plasminogen activator receptor on invasive cancer cells: A prognostic factor in distal gastric adenocarcinoma. Int J Cancer 131: E329-E336. doi:10.1002/ijc.26417

Anderson KM, Czinn SJ, Redline RW, Blanchard TG (2006) Induction of CTLA-4mediated anergy contributes to persistent colonization in the murine model of gastric Helicobacter pylori infection. J Immunol 176: 5306-5313. doi:10.4049/jimmunol.176.9.5306

Arnold IC, Lee JY, Amieva MR, Roers A, Flavell RA, Sparwasser T, Muller A (2011) Tolerance rather than immunity protects from Helicobacter pyloriinduced gastric preneoplasia. Gastroenterology 140: 199-209. doi:10.1053/j.gastro.2010.06.047

Atherton JC, Blaser MJ (2009) Coadaptation of Helicobacter pylori and humans: Ancient history, modern implications. J Clin Invest 119: 2475-2487. doi:10.1172/jci38605

Babicki S, Arndt D, Marcu A, Liang Y, Grant JR, Maciejewski A, Wishart DS (2016) Heatmapper: Web-enabled heat mapping for all. Nucleic Acids Res 44: W147-W153. doi:10.1093/nar/gkw419

Barrozo RM, Cooke CL, Hansen LM, Lam AM, Gaddy JA, Johnson EM, Cariaga TA, Suarez G, Peek RM Jr., Cover TL, et al (2013) Functional plasticity in the type IV secretion system of Helicobacter pylori. PLoS Pathog 9: e1003189. doi:10.1371/journal.ppat.1003189

Blackburn SD, Shin H, Haining WN, Zou T, Workman CJ, Polley A, Betts MR, Freeman GJ, Vignali DA, Wherry EJ (2009) Coregulation of CD8+ T cell exhaustion by multiple inhibitory receptors during chronic viral infection. Nat Immunol 10: 29-37. doi:10.1038/ni.1679

Campbell SL, Khosravi-Far R, Rossman KL, Clark GJ, Der CJ (1998) Increasing complexity of Ras signaling. Oncogene 17: 1395-1413. doi:10.1038/ sj.onc. 1202174

Cancer Genome Atlas Research Network (2014) Comprehensive molecular characterization of gastric adenocarcinoma. Nature 513: 202-209. doi:10.1038/nature13480

Chaturvedi R, Asim M, Romero-Gallo J, Barry DP, Hoge S, de Sablet T, Delgado AG, Wroblewski LE, Piazuelo MB, Yan F, et al (2011) Spermine oxidase mediates the gastric cancer risk associated with Helicobacter pylori CagA. Gastroenterology 141: 1696-1708-2. doi:10.1053/ j.gastro.2011.07.045

Chaturvedi R, Cheng Y, Asim M, Bussiere Fl, Xu H, Gobert AP, Hacker A, Casero RA Jr., Wilson KT (2004) Induction of polyamine oxidase 1 by Helicobacter pylori causes macrophage apoptosis by hydrogen peroxide release and mitochondrial membrane depolarization. J Biol Chem 279: 40161-40173. doi:10.1074/jbc.m401370200

Choi E, Hendley AM, Bailey JM, Leach SD, Goldenring JR (2016) Expression of activated Ras in gastric chief cells of mice leads to the full spectrum of metaplastic lineage transitions. Gastroenterology 150: 918-930.e13. doi:10.1053/j.gastro.2015.11.049

Choi IJ, Kook MC, Kim YI, Cho SJ, Lee JY, Kim CG, Park B, Nam BH (2018) Helicobacter pylori therapy for the prevention of metachronous gastric cancer. N Engl J Med 378: 1085-1095. doi:10.1056/ nejmoa1708423

Cristescu R, Lee J, Nebozhyn M, Kim KM, Ting JC, Wong SS, Liu J, Yue YG, Wang J, Yu K, et al (2015) Molecular analysis of gastric cancer identifies subtypes associated with distinct clinical outcomes. Nat Med 21: 449-456. doi:10.1038/nm.3850

Das S, Suarez G, Beswick EJ, Sierra JC, Graham DY, Reyes VE (2006) Expression of B7-H1 on gastric epithelial cells: Its potential role in regulating $\mathrm{T}$ cells during Helicobacter pylori infection. J Immunol 176: 3000-3009. doi:10.4049/jimmunol.176.5.3000

de Martel C, Georges D, Bray F, Ferlay J, Clifford GM (2020) Global burden of cancer attributable to infections in 2018: A worldwide incidence analysis. Lancet Glob Health 8: e180-e190. doi:10.1016/s2214-109x(19)30488-7

Deng N, Goh LK, Wang H, Das K, Tao J, Tan IB, Zhang S, Lee M, Wu J, Lim KH, et al (2012) A comprehensive survey of genomic alterations in gastric cancer reveals systematic patterns of molecular exclusivity and cooccurrence among distinct therapeutic targets. Gut 61: 673-684. doi:10.1136/gutjnl-2011-301839

Eaton KA, Mefford M, Thevenot T (2001) The role of T cell subsets and cytokines in the pathogenesis of Helicobacter pylori gastritis in mice. J Immunol 166: 7456-7461. doi:10.4049/jimmunol.166.12.7456

Erkan G, Gonul II, Kandilci U, Dursun A (2012) Evaluation of apoptosis along with BCL-2 and Ki-67 expression in patients with intestinal metaplasia. Pathol Res Pract 208: 89-93. doi:10.1016/j.prp.2011.12.002

Ernst PB, Crowe SE, Reyes VE (1997) How does Helicobacter pylori cause mucosal damage? The inflammatory response. Gastroenterology 113: S35-S42. doi:10.1016/s0016-5085(97)80009-1discussion S50.

Figueroa-Protti L, Soto-Molinari R, Calderon-Osorno M, Mora J, Alpizar-Alpizar W (2019) Gastric cancer in the era of immune checkpoint blockade. J Oncol 2019: 1079710. doi:10.1155/2019/1079710

Gebert B, Fischer W, Weiss E, Hoffmann R, Haas R (2003) Helicobacter pylori vacuolating cytotoxin inhibits T lymphocyte activation. Science 301: 1099-1102. doi:10.1126/science.1086871

Halldorsdottir AM, Sigurdardottrir M, Jonasson JG, Oddsdottir M, Magnusson J, Lee JR, Goldenring JR (2003) Spasmolytic polypeptide-expressing metaplasia (SPEM) associated with gastric cancer in Iceland. Dig Dis Sci 48: 431-441. doi:10.1023/a:1022564027468

Huang KK, Ramnarayanan K, Zhu F, Srivastava S, Xu C, Tan ALK, Lee M, Tay S, Das $K$, Xing M, et al (2018) Genomic and epigenomic profiling of high-risk intestinal metaplasia reveals molecular determinants of progression to gastric cancer. Cancer Cell 33: 137-150.e5. doi:10.1016/j.ccell.2017.11.018

Ishigami S, Natsugoe S, Tokuda K, Nakajo A, Okumura H, Matsumoto M, Miyazono F, Hokita S, Aikou T (2003) Tumor-associated macrophage (TAM) infiltration in gastric cancer. Anticancer Res 23: 4079-4083.

Jackson EL, Willis N, Mercer K, Bronson RT, Crowley D, Montoya R, Jacks T, Tuveson DA (2001) Analysis of lung tumor initiation and progression using conditional expression of oncogenic K-ras. Genes Dev 15: 3243-3248. doi:10.1101/gad.943001

Jin Z, Jiang W, Wang L (2015) Biomarkers for gastric cancer: Progression in early diagnosis and prognosis (review). Oncol Lett 9: 1502-1508. doi:10.3892/ol.2015.2959

Kuipers EJ (1999) Review article: Exploring the link between Helicobacter pylori and gastric cancer. Aliment Pharmacol Ther 13: 3-11. doi:10.1046/j.1365-2036.1999.00002.x 
Kusters JG, van Vliet AH, Kuipers EJ (2006) Pathogenesis of Helicobacter pylori infection. Clin Microbiol Rev 19: 449-490. doi:10.1128/cmr.00054-05

Lee A, O'Rourke J, De Ungria MC, Robertson B, Daskalopoulos G, Dixon MF (1997) A standardized mouse model of Helicobacter pylori infection: Introducing the Sydney strain. Gastroenterology 112: 1386-1397. doi:10.1016/s0016-5085(97)70155-0

Lee J, Goh SH, Song N, Hwang JA, Nam S, Choi IJ, Shin A, Kim IH, Ju MH, Jeong JS, et al (2012) Overexpression of IFITM1 has clinicopathologic effects on gastric cancer and is regulated by an epigenetic mechanism. Am J Pathol 181: 43-52. doi:10.1016/j.ajpath.2012.03.027

Lowther DE, Goods BA, Lucca LE, Lerner BA, Raddassi K, van Dijk D, Hernandez AL, Duan X, Gunel M, Coric V, et al (2016) PD-1 marks dysfunctional regulatory T cells in malignant gliomas. JCI Insight 1: e85935. doi:10.1172/jci.insight85935

Martinez LE, O'Brien VP, Leverich CK, Knoblaugh SE, Salama NR (2019) Nonhelical Helicobacter pylori mutants show altered gland colonization and elicit less gastric pathology than helical bacteria during chronic infection. Infect Immun 87: e00904-e00918. doi:10.1128/iai.00904-18

McGarry MP, Stewart CC (1991) Murine eosinophil granulocytes bind the murine macrophage-monocyte specific monoclonal antibody F4/80. J Leukoc Biol 50: 471-478. doi:10.1002/jlb.50.5.471

Mera RM, Bravo LE, Camargo MC, Bravo JC, Delgado AG, Romero-Gallo J, Yepez MC, Realpe JL, Schneider BG, Morgan DR, et al (2018) Dynamics of Helicobacter pylori infection as a determinant of progression of gastric precancerous lesions: 16-year follow-up of an eradication trial. Gut 67: 1239-1246. doi:10.1136/gutjnl-2016-311685

Merchant JL (2005) Inflammation, atrophy, gastric cancer: Connecting the molecular dots. Gastroenterology 129: 1079-1082. doi:10.1053/ j.gastro.2005.07.038

Min J, Vega PN, Engevik AC, Williams JA, Yang Q, Patterson LM, Simmons AJ, Bliton RJ, Betts JW, Lau KS, et al (2019) Heterogeneity and dynamics of active Kras-induced dysplastic lineages from mouse corpus stomach. Nat Commun 10: 5549. doi:10.1038/s41467-019-13479-6

Molina-Castro SE, Tiffon C, Giraud J, Boeuf H, Sifre E, Giese A, Belleannee G, Lehours P, Bessede E, Megraud F, et al (2020) The hippo kinase LATS2 controls Helicobacter pylori-induced epithelial-mesenchymal transition and intestinal metaplasia in gastric mucosa. Cell Mol Gastroenterol Hepatol 9: 257-276. doi:10.1016/j.jcmgh.2019.10.007

Muhlmann G, Spizzo G, Gostner J, Zitt M, Maier H, Moser P, Gastl G, Zitt M, Muller HM, Margreiter R, et al (2009) TROP2 expression as prognostic marker for gastric carcinoma. J Clin Pathol 62: 152-158. doi:10.1136/ jсp.2008.060590

Peleteiro B, La Vecchia C, Lunet N (2012) The role of Helicobacter pylori infection in the web of gastric cancer causation. Eur J Cancer Prev 21: 118-125. doi:10.1097/cej.0b013e32834a7f66

Petersen CP, Mills JC, Goldenring JR (2017) Murine models of gastric corpus preneoplasia. Cell Mol Gastroenterol Hepatol 3: 11-26. doi:10.1016/ j.jcmgh.2016.11.001

Petersen CP, Weis VG, Nam KT, Sousa JF, Fingleton B, Goldenring JR (2014) Macrophages promote progression of spasmolytic polypeptideexpressing metaplasia after acute loss of parietal cells. Gastroenterology 146: 1727-1738.e8. doi:10.1053/j.gastro.2014.02.007

Plummer M, Franceschi S, Vignat J, Forman D, de Martel C (2015) Global burden of gastric cancer attributable to Helicobacter pylori. Int I Cancer 136: 487-490. doi:10.1002/ijc.28999

Radyk MD, Burclaff J, Willet SG, Mills JC (2018) Metaplastic cells in the stomach arise, independently of stem cells, via dedifferentiation or transdifferentiation of chief cells. Gastroenterology 154: 839-843.e2. doi:10.1053/j.gastro.2017.11.278

Riera KM, Jang B, Min J, Roland JT, Yang Q, Fesmire WT, Camilleri-Broet S, Ferri L, Kim WH, Choi E, et al (2020) Trop2 is upregulated in the transition to dysplasia in the metaplastic gastric mucosa. J Pathol 251: 336-347. doi:10.1002/ path.5469
Rogers AB (2012) Histologic scoring of gastritis and gastric cancer in mouse models. Methods Mol Biol 921: 189-203. doi:10.1007/978-1-62703-0052_22

Roth KA, Kapadia SB, Martin SM, Lorenz RG (1999) Cellular immune responses are essential for the development of Helicobacter felis-associated gastric pathology. J Immunol 163: 1490-1497.

Saeidi A, Zandi K, Cheok YY, Saeidi H, Wong WF, Lee CYQ, Cheong HC, Yong YK, Larsson M, Shankar EM (2018) T-cell exhaustion in chronic infections: Reversing the state of exhaustion and reinvigorating optimal protective immune responses. Front Immunol 9: 2569. doi:10.3389/ fimmu.2018.02569

Salama NR, Hartung ML, Muller A (2013) Life in the human stomach: Persistence strategies of the bacterial pathogen Helicobacter pylori. Nat Rev Microbiol 11: 385-399. doi:10.1038/nrmicro3016

Sayi A, Kohler E, Hitzler I, Arnold I, Schwendener R, Rehrauer H, Muller A (2009) The CD4+ T cell-mediated IFN-gamma response to Helicobacter infection is essential for clearance and determines gastric cancer risk. J Immunol 182: 7085-7101. doi:10.4049/jimmunol.0803293

Schindelin J, Arganda-Carreras I, Frise E, Kaynig V, Longair M, Pietzsch T, Preibisch S, Rueden C, Saalfeld S, Schmid B, et al (2012) Fiji: An opensource platform for biological-image analysis. Nat Methods 9: 676-682. doi:10.1038/nmeth.2019

Schmidt PH, Lee JR, Joshi V, Playford RJ, Poulsom R, Wright NA, Goldenring JR (1999) Identification of a metaplastic cell lineage associated with human gastric adenocarcinoma. Lab Invest 79: 639-646.

Shi Y, Liu XF, Zhuang Y, Zhang JY, Liu T, Yin Z, Wu C, Mao XH, Jia KR, Wang FJ, et al (2010) Helicobacter pylori-induced Th17 responses modulate Th1 cell responses, benefit bacterial growth, and contribute to pathology in mice. J Immunol 184: 5121-5129. doi:10.4049/jimmunol.0901115

Shvartsur A, Bonavida B (2015) Trop2 and its overexpression in cancers: Regulation and clinical/therapeutic implications. Genes Cancer 6: 84-105. doi:10.18632/genesandcancer.40

Stoicov C, Fan X, Liu JH, Bowen G, Whary M, Kurt-Jones E, Houghton J (2009) Tbet knockout prevents Helicobacter felis-induced gastric cancer. J Immunol 183: 642-649. doi:10.4049/jimmunol.0900511

Suerbaum S, Michetti P (2002) Helicobacter pylori infection. N Engl J Med 347: 1175-1186. doi:10.1056/nejmra020542

Talarico S, Leverich CK, Wei B, Ma J, Cao X, Guo Y, Han G, Yao L, Self S, Zhao Y, et al (2018) Increased H. pylori stool shedding and EPIYA-D cagA alleles are associated with gastric cancer in an East Asian hospital. PLoS One 13: e0202925. doi:10.1371/journal.pone.0202925

Tang YL, Gan RL, Dong BH, Jiang RC, Tang RJ (2005) Detection and location of Helicobacter pylori in human gastric carcinomas. World J Gastroenterol 11: 1387-1391. doi:10.3748/wjg.v11.i9.1387

Velin D, Favre L, Bernasconi E, Bachmann D, Pythoud C, Saiji E, Bouzourene H, Michetti P (2009) Interleukin-17 is a critical mediator of vaccineinduced reduction of Helicobacter infection in the mouse model. Gastroenterology 136: 2237-2246.e1. doi:10.1053/j.gastro.2009.02.077

Yamaguchi H, Goldenring JR, Kaminishi M, Lee JR (2002) Identification of spasmolytic polypeptide expressing metaplasia (SPEM) in remnant gastric cancer and surveillance postgastrectomy biopsies. Dig Dis Sci 47: 573-578. doi:10.1023/a:1017920220149

Zayac A, Almhanna K (2020) Esophageal, gastric cancer and immunotherapy: Small steps in the right direction? Transl Gastroenterol Hepatol 5: 9. doi:10.21037/tgh.2019.09.05

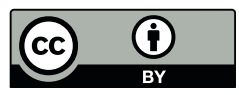

License: This article is available under a Creative Commons License (Attribution 4.0 International, as described at https://creativecommons.org/ licenses/by/4.0/). 